\title{
Well integrity management in mature fields: a state-of-the-art review on the system structure and maturity
}

\author{
Mostafa S. Yakoot ${ }^{1} \cdot$ Ahmed A. Elgibaly $^{2} \cdot$ Adel M. S. Ragab $^{2} \cdot$ Omar Mahmoud $^{3}$ (D)
}

Received: 7 December 2020 / Accepted: 26 March 2021 / Published online: 7 April 2021

(c) The Author(s) 2021

\begin{abstract}
Nowadays, oil and gas $(\mathrm{O} \& \mathrm{G})$ fields are maturing and creating new threats. This urged the operating companies and industry researchers to have intensive focus on well integrity (WI). Building Well Integrity Management System (WIMS) establishes standardized criteria to guarantee that integrity of all wells is preserved during their lifespan, functions properly in healthy condition, and is able to operate consistently to fulfill the expected production/injection demands. Moreover, exploration and production (E\&P) companies put Health, Safety, and Environment (HSE), assets, production, local and public image as top priority in their businesses. Having effective WIMS at all times and throughout all well phases reduces the frequency of major integrity failures and thus helps companies to be on track regarding the aforementioned considerations. In this paper, we present a comprehensive review on the system structure and maturity of WIMS in mature fields. This state-of-the-art review highlights the efforts made by different O\&G operators all over the world to develop and start application of WIMS, which varies widely due to differences in the main WI challenges that are recurring in each field or concession. Moreover, it lists the goals and expounds the stages of launching effective WIMS. In addition, the key elements, around which the WI program is structured, are discussed and presented for various O\&G operators. The major five elements of accountability and responsibility, well operations procedures, well intervention procedures, tubing and casing integrity program, and wellhead and X-tree maintenance are overviewed. Furthermore, this paper assesses WIMS sustainability through demonstration of WI maturity models, scrutiny of maturity levels, and analysis of transformative elements to convert WIMS into strategic framework. Risk management systems as well as application of analytics in WIMS are also covered and thoroughly discussed. In reviewing the literature covering different assets—all over the world for the last 15 years—it was found that real progress was made in WI area, and WIMS established in many operating companies through different approaches. However, the introduced systems lack universality and few of them are applying artificial intelligence as powerful tool for boosting the system. The most obvious finding to emerge from the analysis is that WIMS is crucial system that must be implemented and matured for well lifecycle. The findings of this study can help operating companies for better framing of key pillars to have robust and operable WIMS throughout different fields and concessions, hence improving the well integrity performance worldwide.
\end{abstract}

Keywords Well integrity management system $\cdot$ Maturity model $\cdot$ Risk assessment $\cdot$ Oil and gas fields $\cdot$ Well lif cycle . Review

$\begin{array}{ll}\text { Abbreviations } \\ \text { CTU } & \text { Coiled tubing operation } \\ \text { DIKW } & \text { Data information knowledge wisdom } \\ \text { E\&P } & \text { Exploration and production } \\ \text { EIA } & \text { Environment impact assessment }\end{array}$

Omar Mahmoud

omar.mahmoud@aggienetwork.com

1 Gulf of Suez Petroleum Co. (GUPCO), Cairo, Egypt

2 Suez University, Suez, Egypt

3 Future University in Egypt (FUE), New Cairo, Egypt
FMECA Failure mode, effects, and criticality analysis

GOS

HAZID

HAZOP

HSE

ISO

KPI

NORSOK

O\&G

OGUK

OLF

RA

Gulf of Suez

Hazards identification

Hazards and operability study

Health, Safety, and Environment

International Organization for Standardization

Key performance indicator

Norwegian Shelf's competitive position

Oil and gas

Oil \& gas United Kingdom

Norwegian Oil Industry Association

Risk assessment

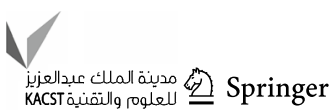




$\begin{array}{ll}\text { RMS } & \text { Risk management system } \\ \text { SSSV } & \text { Subsurface safety valve } \\ \text { SSV } & \text { Surface safety valve } \\ \text { WI } & \text { Well integriy } \\ \text { WIM } & \text { Well integrity management } \\ \text { WIMS } & \text { Well integrity management system }\end{array}$

\section{Introduction}

WI issues may arise in any well, producing or not, particularly old wells that have been constructed as per the regulations and standards of their construction date. The standards of well construction have improved over time in terms of safety specifications. In addition, several wells that conform to current safety requirements may still have problems related to integrity.

Although the necessity to enhance the integrity of wells is recognized, enhancement activities have been limited by past budget constraints. It therefore became necessary to effectively manage the wide range of WI problems, by adopting a concept of WIMS. Application of WIMS leads to;

- controlling all WI issues,

- establishing minimum WI requirements,

- restoring and protecting oil/gas opportunities at risk, and

- adding oil and/or gas gains from workover/recompletion options during wellbore reentry.

WI system revolves around the design and control of subsystem/components to ascertain smooth operations, conformity with industry practices, legislative authority criteria, internal corporate procedures, and integrating learned lessons from relevant events.

The emphasis is on risk assessment (RA) and categorization approaches that are applied to handle a well's life period during field interventions and/or operations. WI is a multifarious management system that covers the life of a well from design phase to abandonment phase. Old RA techniques do not suit the modern ages where internet of things is invading all industries.

WI problems occur at some point in the life of mostly all oil and gas $(O \& G)$ fields. The main challenges associated with those WI problems are the accurate determination of the status of safety critical equipment within well barrier envelope, the probability and consequences of any posed risk, and the proper risk classification of the well status where appropriate mitigation can be advised.

The well risk status was usually known through risk register meeting among all of the involved teams where brainstorming is the key to determine and analyze all possible risks. In addition, the industrial safety matrix was used to identify probability and consequences of the predicted risks. However, this methodology is affected by knowledge and subjective experience of the involved teams. Determining the accurate risk rank of any well is of utmost importance when it comes to workover budget, repair costs, and production deferral impact. Generally, risk ranking performs the significantly important functions as illustrated in Fig. 1.

Well risk category is an imperative parameter that specifies the status of wells to WI engineers so that they can monitor and boost the WI of the system (surface and subsurface). Ironically, risk classification in individual wells is not monitored frequently and, wherever they are, spreadsheets are employed, which carry their own inherent error. Spreadsheets provide accepted results; however, they are subject to data entry engineers and in many times to their understanding and interpretation of data. Sometimes data are impractical to use in variable conditions and errors show up in spreadsheets, which lead to erroneous risk weight and subsequent inaccurate calculations that make use of this risk category misleading. Moreover, the orthodox safety-matrix classification technique requires lengthy stages of data collection. In this technique, a scenario-based RA is employed to distinguish different categories. This presents potential

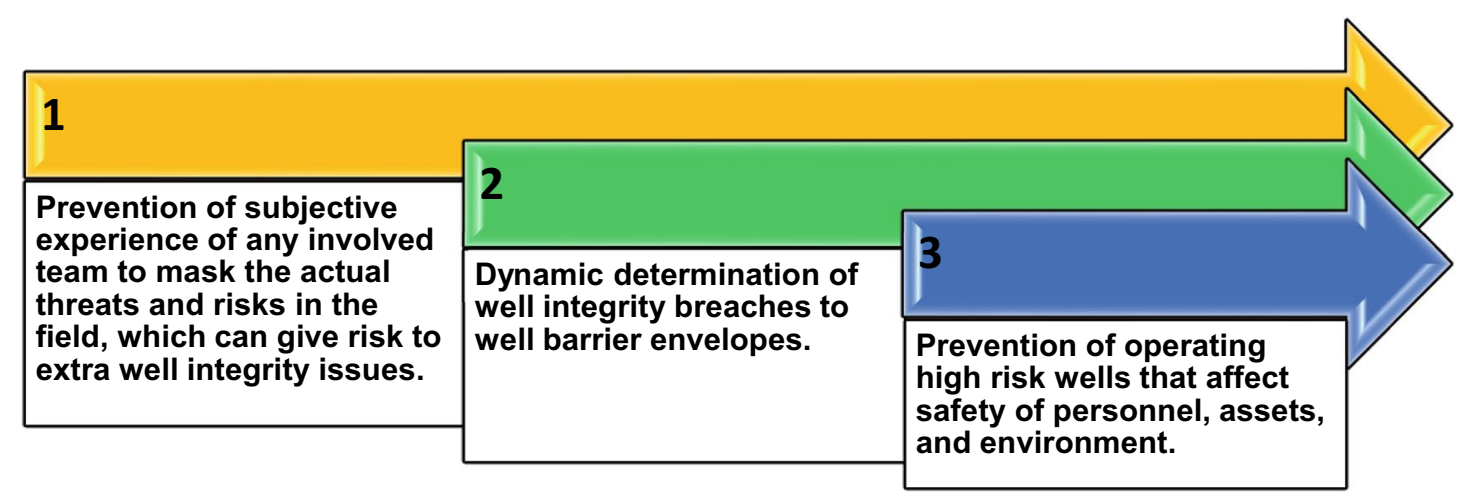

Fig. 1 Functions of risk ranking

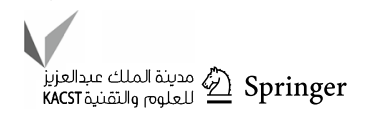


hazardous operation of some risky wells, which are dangerous or difficult to control in case of impairments. Accordingly, a model that can accurately predict risk category will provide prodigious advantage to engineers while running both green and brown fields to enhance WI monitoring in real time.

To the best of the authors' knowledge, there is no research with solid foundation that recapitulates the advancements and experiences in the application of WIMS and its core principles. The objective of this paper is to a) overview the evolution of well integrity and consequences of well integrity impairments, b) elucidate the current WIMSs applied in different assets around the world with profound investigation and analysis, c) thrive the reader and industry professionals with controlling parameters of WIMS along with distinctive milestones for each system application, d) shed light on the uncontested versatility of WI program structure that stems from prerequisites of each operator before applying the program, e) evaluate WIMS maturity by benchmarking of the measured maturity level with best renowned standards and practices, f) explore double barrier concept in WI and describe some of the common WI problems where breach and failure of envelopes occur, g) investigate the multifarious approaches of risk assessment during evaluation of well integrity failure, $h$ ) analyze the impact of analytics application on well integrity performance, and i) show the economic feasibility of proper WIMS application through relating the advantages of holistic WIMS with repair/intervention costs and production.

It is anticipated that this review will represent a handy and valuable guide for both companies and researchers for the development of WIMS and more understanding of system critical features during well life cycle.

Figure 2 illustrates the sequence of steps taken to achieve the aforementioned objectives of the work. This paper firstly gives an explanation of the well integrity discipline and its evolution. Secondly, WIMS and its major pillars are discussed. After that, WI program structure is detailed and double barrier concept is explored. Then, WIMS maturity and benchmarking are analyzed. Further, diverse approaches of RA are compared. After that, analytics and applications of WIMS are reviewed. Finally, conclusions and recommendations are drawn.

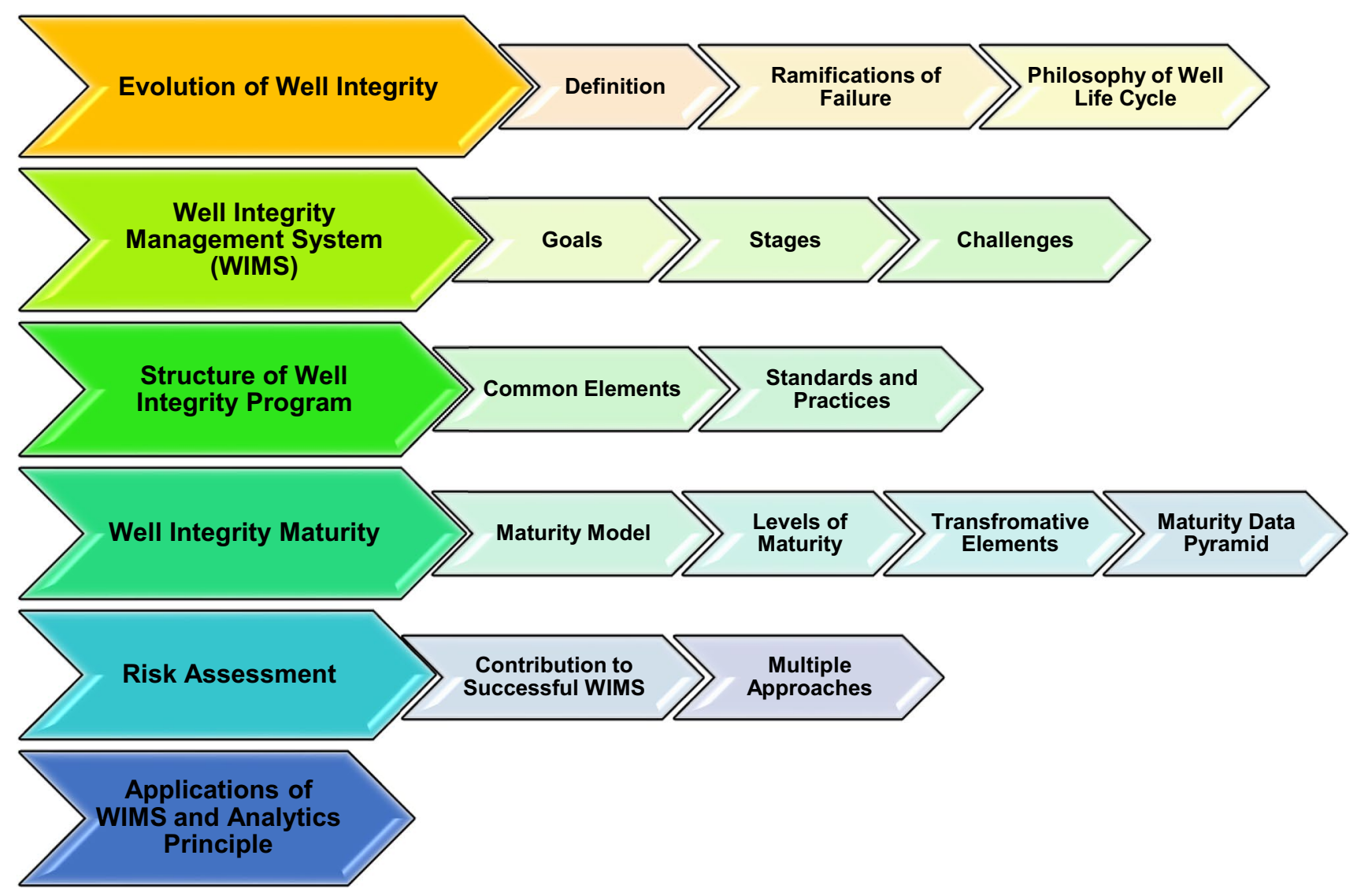

Fig. 2 General sequence of the steps of research work 


\section{Well integrity}

$\mathrm{O} \& \mathrm{G}$ is a special business in which we operate in near proximity to vast supplies of hazardous substances. Being willing to deal with such potentially dangerous substances in a safe and environmentally friendly way is essential to the sustainability of O\&G business (Gouda and Aslam 2018). According to Kiran et al. (2017) and Ma et al. (2020), the ramifications of WI issues can be one or more of the following;

- loss of human lives where personnel can be killed or injured.

- environmental damage.

- capital loss represented in assets.

- damage and/or loss of equipment.

- financial loss and bankruptcy in some cases.

- loss of company reputation that results in lost contracts.

- extra regulation from government such as moratorium.

History reveals many cases of well-related accidents, such as Montara blowout in Australia, 2009, and British Petroleum accident in Gulf of Mexico, 2010. Such serious accidents inform us of the possible risks during well life cycle operations and are some of the key reasons for the increased emphasis on asset and WI. Such significant events do not arise because of a breakdown of one piece of equipment or an individual's incorrect action. They are embodied by a sequence of equipment defects, staff activities, processes, and procedures (Gouda and Aslam 2018).

Amid the strategic concerns of the O\&G sector, well integrity management (WIM) actually plays a crucial part. It enables two main goals to be met concurrently by reducing the possibility of unregulated leakage of hydrocarbons and prolonging the existence of wells, benefiting the most of the reservoirs (D'Alesio and Caramanico 2015). Ultimately, WI is exceedingly important because it ensures adequate safe level during continuous production operations (Miraglia 2020). Moreover, WI is a mandatory requirement for all types of well services including production and injection (Reichetseder 2016).

Wells are the most critical element of the asset as the possible effects of a well failure can be disastrous. Following a series of high-profile accidents, no operator should claim ignorance of the immense harm that may be done by a significant, well-related accident (Spowage et al. 2018). It is reported that $30-45 \%$ of active wells worldwide have some kind of integrity issues. The main problem is sustained annulus pressure, which implies a persistent leakage route from the active feeding source, usually the reservoir. Other specific issues are the malfunction/breakdown of safety critical barriers (Fig. 3) and other well barriers due to deficiency of the installed components. There are still severe problems of corrosion failure of completion strings,

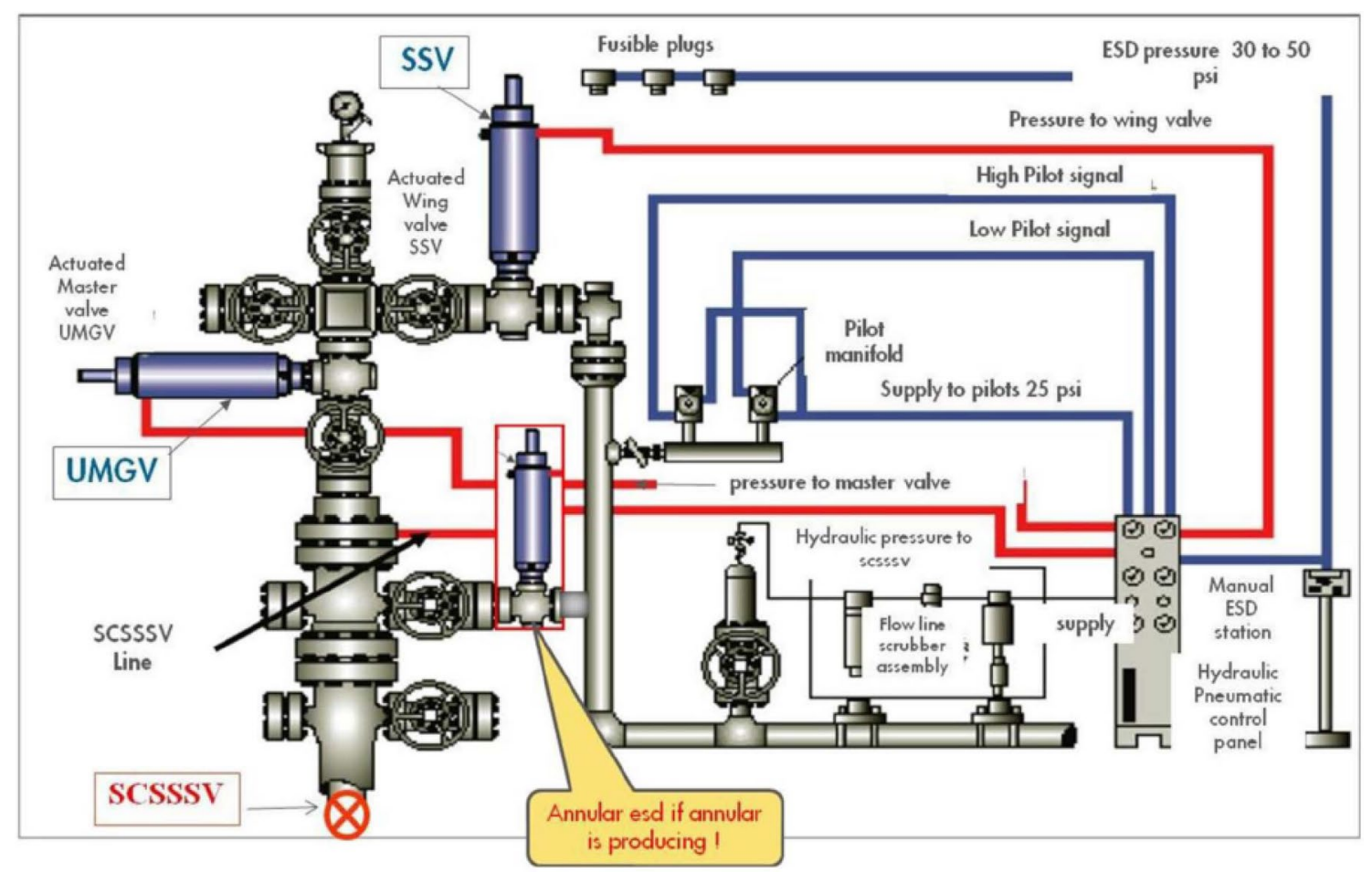

Fig. 3 Safety critical elements in wells connected to emergency shutdown system (Gouda and Aslam 2018)

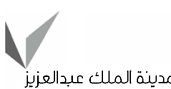

مدينة الملك عبدالعزيز Springer 


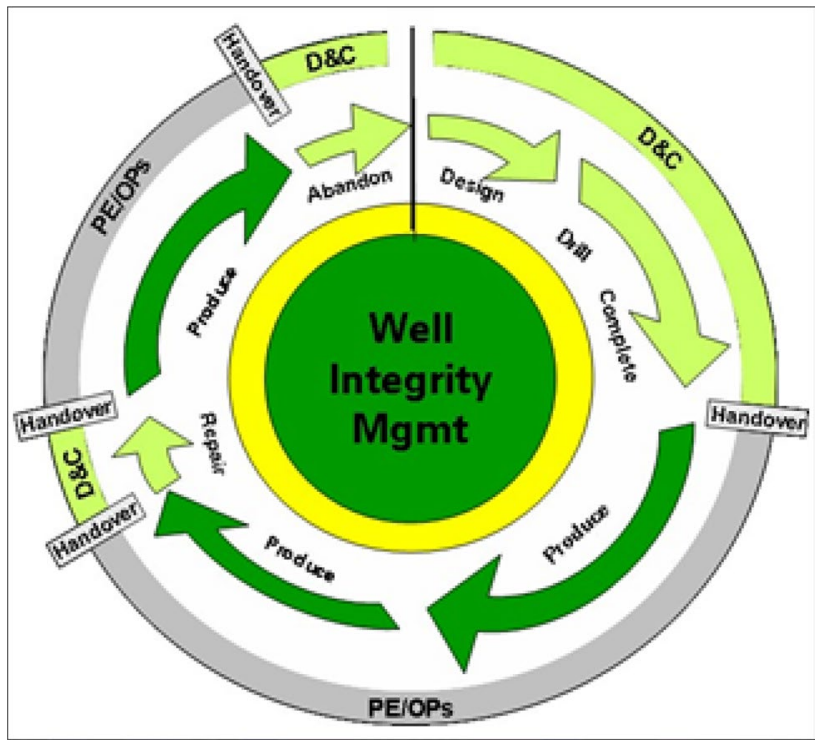

Fig. 4 WIMS is a life cycle system (Anders et al. 2008)

casing, wellhead, and X-tree valves, offshore conductors, and several other causes (Smith et al. 2015).

Gouda and Aslam (2018) linked between preventing serious accidents and handling potential dangers throughout well life cycle. The control of major accident hazards during that well life cycle means the conservation of integrity in the well life cycle phases. WIMS is essentially designed to create a structure for handling significant hazards and incidents over the well life cycle as described in Fig. 4.

Ajimoko (2016) believed that business risk is unavoidable due to uncertainty and challenges of well operations. This makes effective control of reasonable business risks as a significant element of enhancing well construction, company performance, and bottom-line profits.

According to Wakama et al. (2004), WI is a critical element in various phases of a well's life cycle. It starts with planning constructing, operating, maintaining, and finally abandoning the well. To preserve their integrity, all wells shall meet this definition, mitigating the risks to health, safety, and environment (HSE). The life cycle of a well is supposed to be consistent throughout its initial phase. The well construction process can be affected by some degrading problems such as casing wear, corrosive fluids, and drag forces, but its servicing would get harder and harder as the asset matures. In this situation, improved diligence and stronger surveillance are required to ensure that the asset is safe and has trouble-free service (Kumar 2014).

As shown in Fig. 5, Al Khamis et al. (2014) introduced new prospect of comprehensive process of preparation, scheduling, implementation, data processing, data analysis,

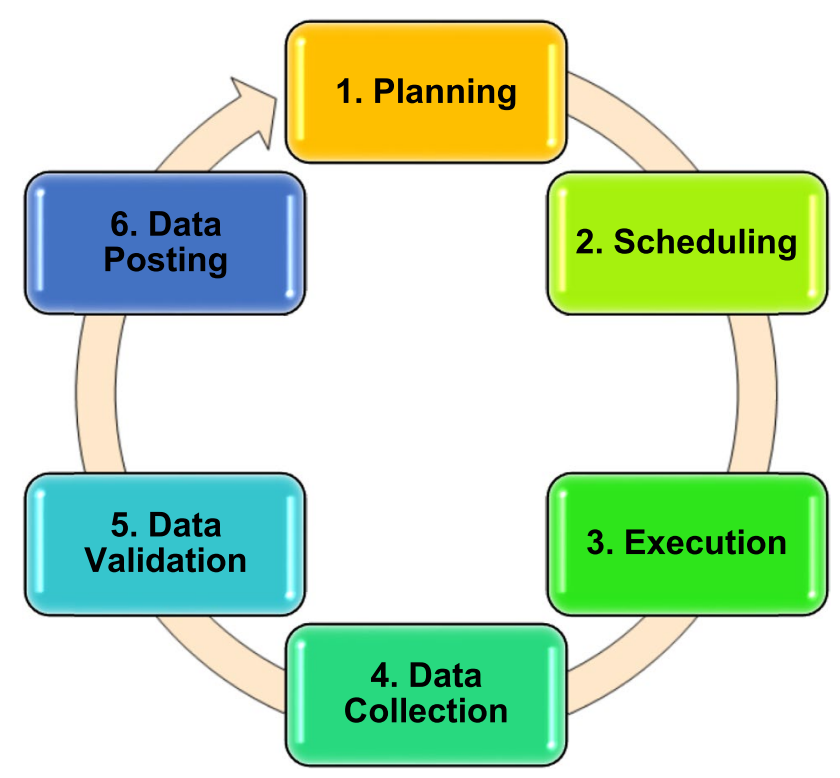

Fig. 5 Scheduling and tracking of well integrity surveillance (Al Khamis et al. 2014)

and data reporting systems to enhance organizational performance across the enterprise.

Philosophy of WIM claims that all well containment barriers are always vulnerable which mandates testing and verifying these barriers frequently (Ceray et al. 2014). Life cycle of any well demands systematic WIM and hydrocarbon flow control. This is now directive by all recent regulations and standards. The operation phase is an extending phase throughout the life cycle of any well (Benjamin and Cosmas 2018).

\section{Evolution of well integrity}

WI has lately been the primary focus in the O\&G industry since serious accidents have occurred, which can mainly be attributed to a deficient integrity of assets. WIM has to be implemented and new fields are to be developed considering implementation of WI aspects throughout wells' life cycle (Gilbert et al. 2013).

WI came to a clear perspective in the oil industry very late. Before, it was a task involved within the department of petroleum engineering. Devoted WI divisions are now established and a comprehensive WI policy in place (Chishti et al. 2015). According to Brechan et al. (2018a), WI is a pretty recent field of specialty that the industry has witnessed some increasing commitment and shift toward a life-cycle approach. There are a growing emphasis and concentration on maintaining WI effectively with more streamlined and cost-effective resources processes and solutions (Fjågesund 2018). In their extended research, Brechan et al. (2019) 
confirmed that WI is a comparatively new specialty, where regulations and standards have developed dramatically in the last years. There are also ranges of essential subjects that need to be established.

When O\&G assets mature, WI assurance becomes more necessary to ensure the wells are in safe condition. Integrity of assets should be core elements of any company vision (Al Muailu et al. 2013). Human interaction is among the most common root causes of well control and WI incidents (Hauge et al. 2013).

In summary, WI practices have been considered as an enforcement practices and an expense driver. This does not exist anymore. Over the last decade, a variety of industry efforts have demonstrated that WI problems are a significant contributor to field interruptions and production losses, particularly as well inventory matures. This has been recognized by the industry and a variety of initiatives has been implemented. A variety of recommendations, specifications, and regulations are issued by the International Organization for Standardization (ISO), the Norwegian Shelf's Competitive Position (NORSOK), the Oil \& Gas United Kingdom (OGUK), and the Norwegian Oil Industry Association (OLF), which have evolved as a shared understanding of the market. A number of companies have released internal operating guidelines (Corneliussen 2017).

The NORSOK Standard D-010 (2013) introduced by the Norwegian O\&G industry describes well integrity as the "Application of technical operational and organizational solutions to reduce the risk of uncontrolled release of formation fluids throughout a well's life cycle." The goal is to reduce the chance of fluid escaping from the formation. It involves all leaks from formations to the environment and the subterranean formations. All aspects of operation in wells, from design phase to abandonment and during well interventions and service activities, should be incorporated.
Daghmouni et al. (2010) outlined benefits of WI as depicted in Fig. 6.

On the other side, low oil prices in recent times have forced major international companies to agree the selling of their stake to other operators or to return fields to national oil corporations at the end of their contract duration. This poses a variety of obstacles for new operators, the most important of which is how to handle the asset efficiently and cost effectively. The value of well stock in mature assets will only be completely exploited if wells are maintained and all potential WI problems are resolved (Spowage et al. 2018).

\section{Well integrity management system}

Well Integrity Management System (WIMS) is a process where integrity of wells is continually managed, assessed, and verified. This is repeated for all life cycles of the well. WI is simply to keep hydrocarbon inside the pipe or its designated route starting from well construction, operation, and abandonment. WIMS specifically aims at keeping risk to people and environment as low as reasonably practical during all well cycles. WIMS can be schematically illustrated as shown in Fig. 7.

The key goals of WIMS are to define well design criteria, construct wells in compliance with design criteria, and operate wells within specific criteria. WIMS process for any business goes through four stages, which are direction, system development, implementation, and result stages. Table 1 shows a briefly definition of each stage.

The WIMS has different benefits, which can be summarized as (Elrefai et al. 2017):

- Ensure all organization teams are having the same trusted and quality-assured information of WI.

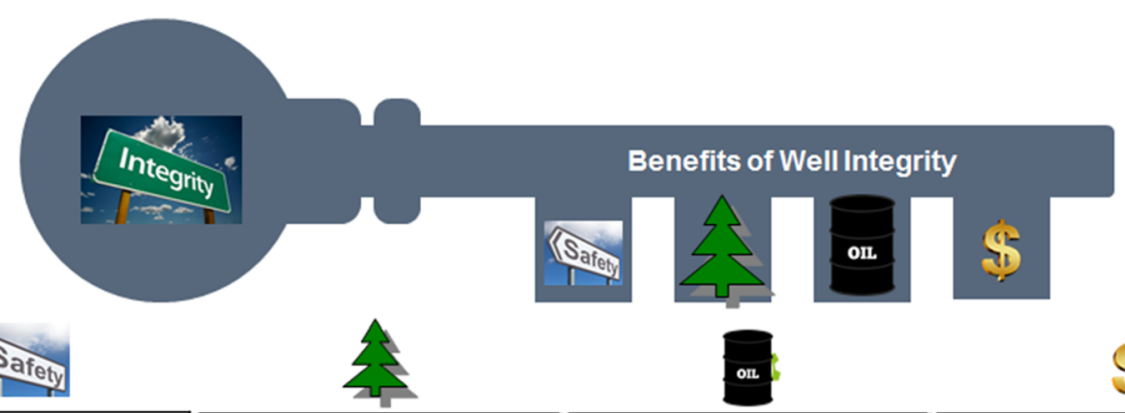

\begin{tabular}{|c|c|c|c|}
\hline Safety & Environment & Production & Operating Cost \\
\hline $\begin{array}{l}\text { Decrease frequency of } \\
\text { integrity failures and } \\
\text { probability of uncontrolled } \\
\text { flow events. }\end{array}$ & $\begin{array}{l}\text { Better control of unwanted } \\
\text { flow to the surroundings } \\
\text { and environment. }\end{array}$ & $\begin{array}{l}\text { Decrease downtimes through } \\
\text { continuous preventive } \\
\text { measures and hence increase } \\
\text { production capacity. }\end{array}$ & $\begin{array}{l}\text { Reduce operating cost } \\
\text { throughout well life cycle by } \\
\text { warranting accurate well } \\
\text { construction and operation. }\end{array}$ \\
\hline
\end{tabular}

Fig. 6 Benefits of well integrity (Daghmouni et al. 2010)

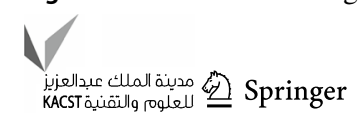


Fig. 7 WIMS is a process where integrity of wells is continually managed, assessed, and verified (Daghmouni et al. 2010)

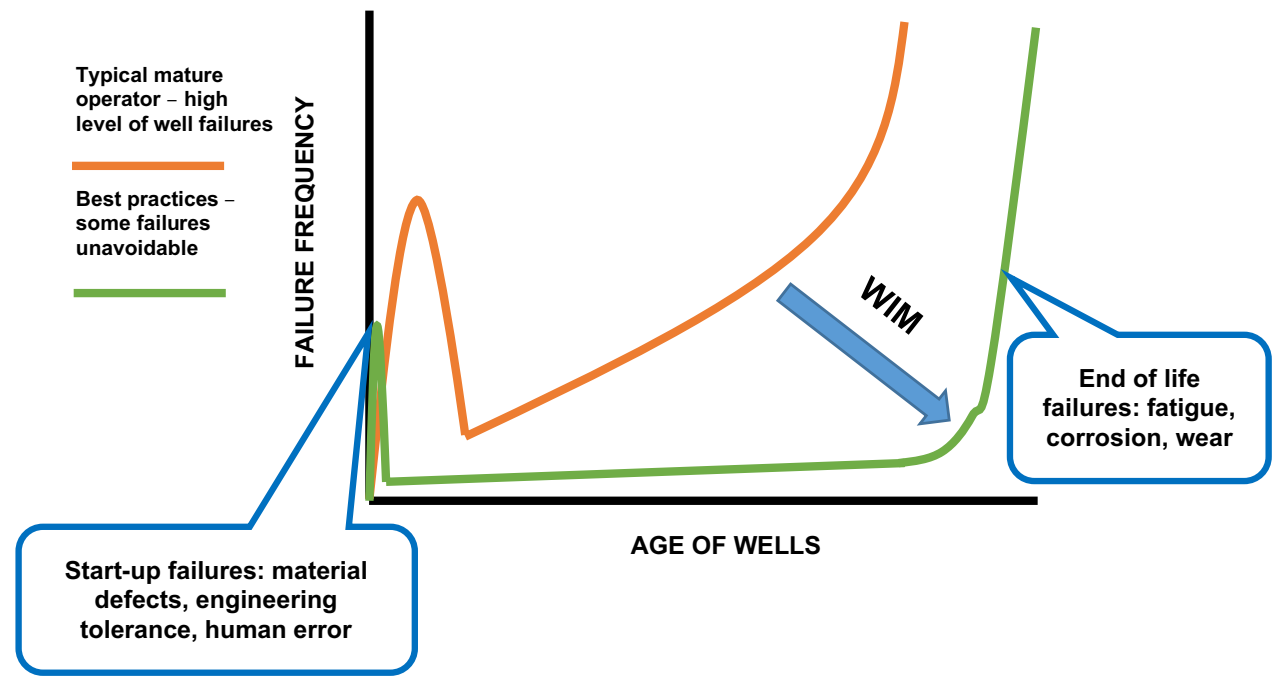

Table 1 Stages of WIMS process

\begin{tabular}{ll}
\hline Stage of WIMS & Definition \\
\hline Direction & Senior management advise to establish the system \\
Development-system & Define, develop, and complete minimum well integrity Pillars of the system along with required documents \\
Implementation & Integrate the system within corporate processes, standards, and recommended practices \\
Result & The corporate has its own integrity Key Performance Indicator where integrity performance is monitored. \\
& Continuous improvement cycle is applied \\
\hline
\end{tabular}

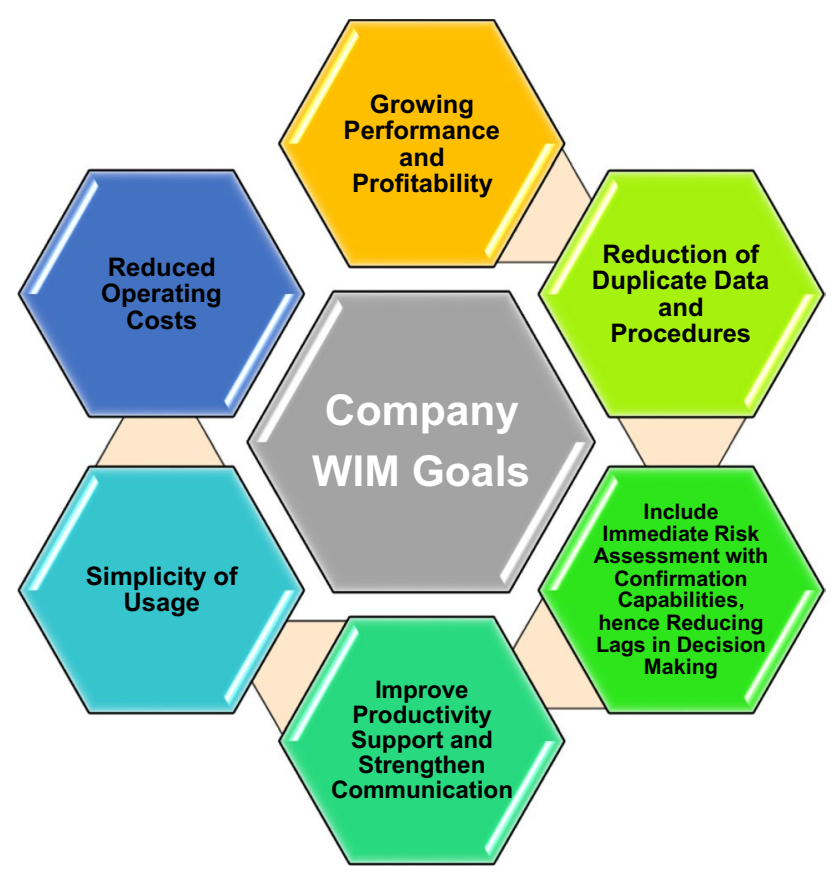

Fig. 8 Goals of a company in terms of Well Integrity Management
- Reduce overload of data and concentrate only on the information required to take critical decisions in appropriate time.

- Considerably decrease overall assessment time by using brainstorming capabilities.

- Simplify early detection of WI impairments and offer easier way to analyze and diagnose the root cause of any failure.

Elrefai et al. (2017) recognized the implementation of a WIM program to be a crucial contribution in making successful strategic choices concerning production strategies for every company. They defined the goals of a company in terms of WIM as constructed in schematic shown in Fig. 8.

Ahmed et al. (2007) developed and started implementation of WIMS in Gulf of Suez (GOS). They evaluated WI requirements and found that wells having different problems operated with high to moderately low potential risk. The authors defined envelope of high-risk wells and communicated to all levels in the company. They intensively studied similar facilities in mature oil fields, operating offshore, and resulting in the need for thorough recognition of the (1) technical authority designation, (2) competencies and skills of involved engineers and technicians, (3) combined standard for WI during both production and drilling phases, (4) rig/barge prerequisites for approach/ 
leaving platforms, (5) annulus management policy, (6) setting criteria for minimum requirements of barriers during well work and related dispensation work, and (7) document control for the existing standards.

The thorough assessment also reflected some other problems, such as the (1) monitoring data of surface pressures and temperatures at wellhead, (2) integrity of completion, (3) testing and maintenance of surface and subsurface safety valves (SSV and SSSV), (4) testing and maintenance of X-tree, (5) diagnosis and management of scale problem.

Similarly, Al-Ashhab et al. (2004) and Al Khamis et al. (2014) identified that the purpose of creating WIMS is to establish standardized criteria to guarantee that integrity of all wells is preserved during their lifespan, functions properly in healthy condition, and is able to operate consistently to fulfill the expected production/injection demands. The WIMS should be applied to different types of wells including oil, gas, water producers and water, gas injectors. The system aims at ensuring quality and healthiness of all critical WI components either downhole or at the wellhead.

WI in the individual well is focused on establishing and maintaining isolation barriers. A well is called integral according to WIMS requirements if there are at least two independent and tested barriers all the time within each flow route between the hydrocarbon reservoir and surroundings. WIMS puts considerable focus on the task-based approach (forecasting and tackling the problem before it comes up) that can handle many tangible benefits and improvements such as decreased disruption, improved safety and control factors, and minimal unforeseen maintenance activity.

Al-Ashhab et al. (2004) addressed significant well challenges that would affect a well operational-integrity and functionality. It involves, but not limited to:

- X-tree and well head components,

- downhole safety valve,

- gas lift injection valves,

- annulus management,

- landing base inspection,

- downhole completion integrity and accessibility,

- suspension of operation activities,

- different well intervention methods (wire Line, pumping, coiled tubing operation (CTU), and

- Risk Management System (RMS), auditing process, etc.

Application of WIMS varies widely among different O\&G operators all over the world due to differences in the major WI challenges that are recurring in each field or concession. The application of such system not only acts as a predictive tool for any integrity problem, but also used as preventive method for maintaining healthiness of field assets.
Samad et al. (2007) confirmed that setting up devoted WI entities is essential for the business to ensure that their assets are continued to operate at low relatively low risk. The authors listed three key elements of the WIMS namely; data collection, risk analysis and classification, and database of WIMS. Added to them are well certificates.

An extensive data collection must be established and obtained in order to initiate an unbiased risk classification of a well. The data needed for RA are divided into two groups: office data and field data. Office data include production figures, job reports, logs, and schematics (drilling data, casing, cementing jobs, cement evaluation logs, and completion details), data about production rates and well status (well production phase), and flow assurance data such as corrosion and scale management. On the other side, field data include physical readings at the wellhead, and testing results, such as annuli pressure readings (based on predetermined frequency matching WI policy), X-tree testing and wellhead cavity checking (it is important to have to detailed information about the condition/status of the wellheads and X-trees on each well in the field), and frequent check of downhole safety valve integrity and completion string.

\section{Structure of well integrity program}

Bybee (2007) and Anders et al. (2008) emphasized on policies and practices that are applied to handle a well's life period during field interventions and/or operations. Figure 9 shows the relationship between local events, applied policy, and standards (Anders et al. 2008, 2015).

WI is a multifarious management system that covers the life of a well from design phase to abandonment phase. WI system revolves around the design and control of subsystem/components to ascertain smooth operations, conformity with industry practices, legislative authority criteria, internal corporate procedures, and integrating learned lessons from relevant events. The WI program is structured around five elements: accountability and responsibility, well operations procedures, well intervention procedures, tubing and casing integrity program, and wellhead and X-tree maintenance.

Accountability and responsibility Precise definition of responsibilities and accountabilities is essential to maintaining WI, in other words, who performs the specific job and who manages resources and guarantees the execution of a specific task.

Well operating procedures Well operations represent the largest facet of the life of a well. These activities are controlled through a system of handover process, qualified crews, and appropriate practices. Specific designation of well ownership accountabilities is essential to safe well operations. Well ownership will be passed many times during a well life between drilling, operations, and servicing 
Fig. 9 Relationship between Alaska local events, policy, and standards (Anders et al. 2008)
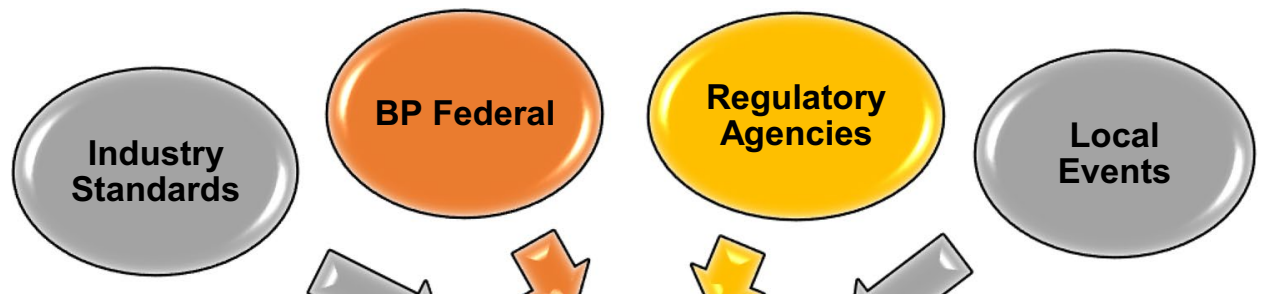

.
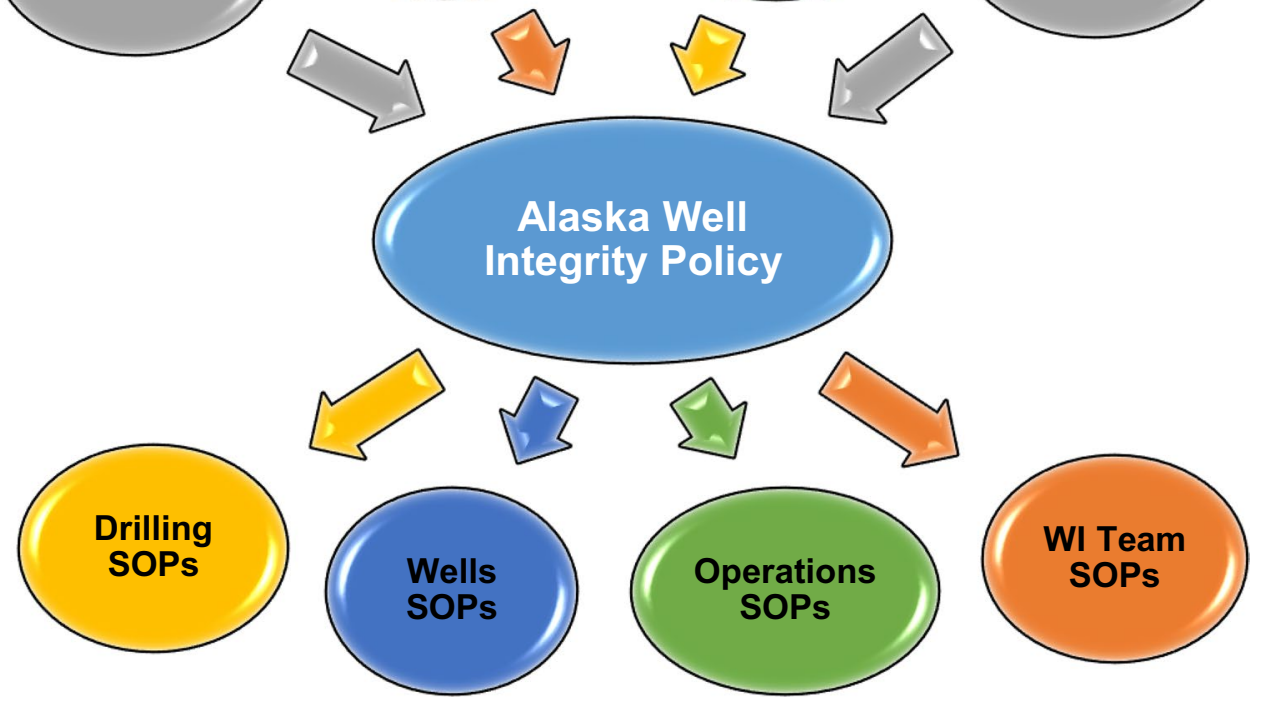

teams. Typically drilling "hands-over" wells with two qualified well barriers to operations.

Generally, tubing, packer, gas lift mandrels, and wellhead equipment are the primary well barrier system. The secondary well barrier is competent casing string and qualified wellhead equipment.

A significant step is the transfer of documents to production team from the well construction department. Any well design element that is essential to the well's safety or operational reliability should be clearly identified in the handover documents. For example, the content of the handover involves well construction components and pressure testing charts for each part. In addition, all challenges and problems encountered during drilling or completion should be addressed and mentioned in well bore sketch. For all kinds of wells and operation conditions, clearly written standard operating procedures were created.

Well intervention procedures After writing the job program, well service operations are performed following the program. Standardized procedures were established for all regular operation activities.

Tubing and casing integrity program Managing the well stock barrier status is an essential element of the WIMS. Having explicitly defined pressure limitations combined with an effective monitoring program makes it easier to identify and handle wells with physical anomalies. All operable wells must have properly working pressure gauges on each annulus. When an annulus pressure is higher than the limit, it is essential to initiate suitable action. This may be bleeding and recording the bled pressure values. Annulus

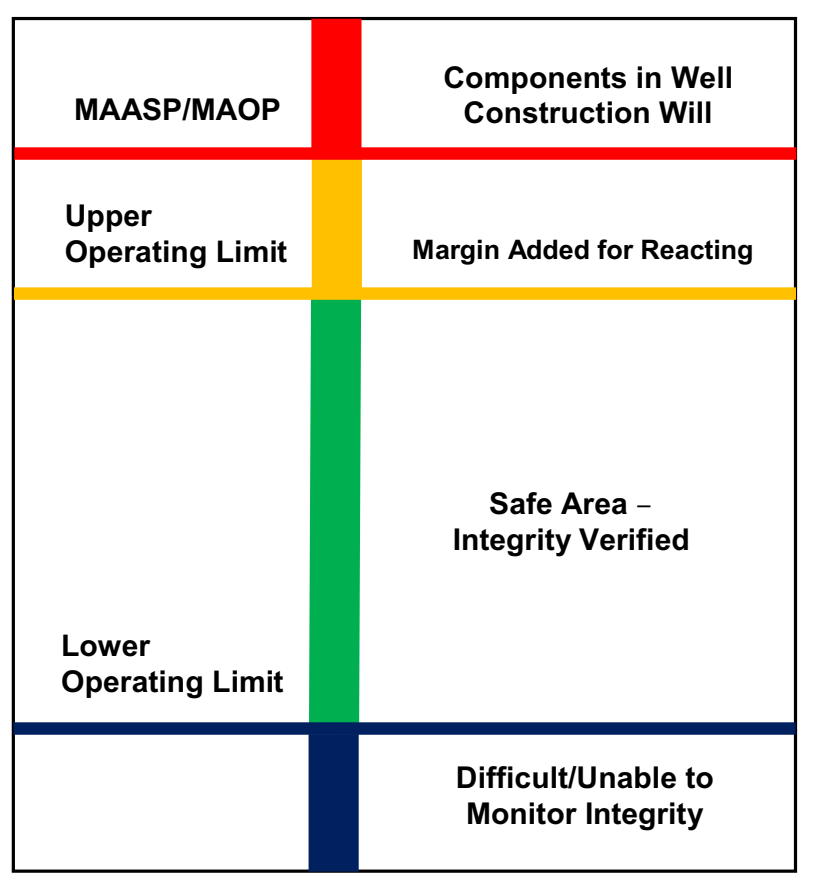

Fig. 10 Operation limits of an annulus as delineated by both API RP 90 and ISO 16,530-1 (Brechan et al. 2018a)

pressure values are continuously monitored during any intervention job.

Nowadays, there are individuals in the field reading analog gauges every day. In the future, a modern field operation will use wireless technologies. Where analog gauges are usable today, a signal may be sent to a "central hub" 


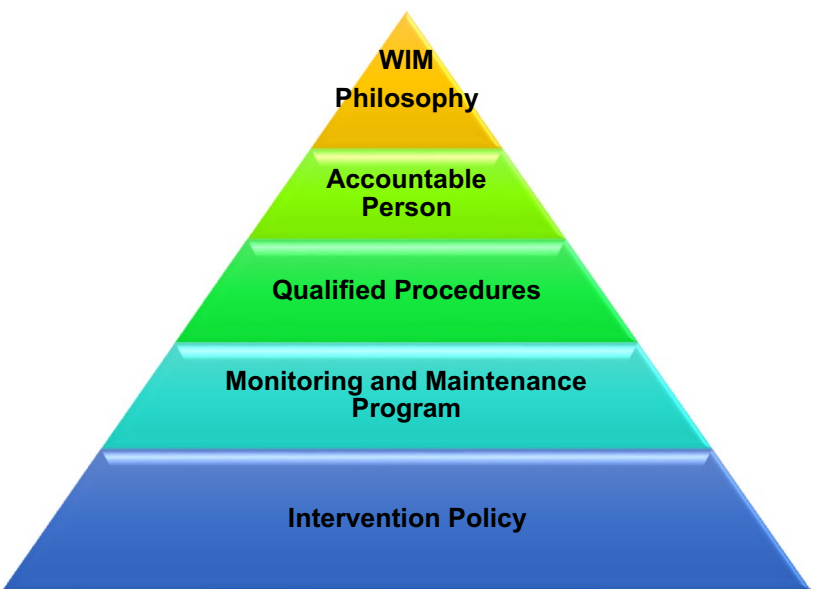

Fig. 11 Elements of successful well integrity management system (Andersen 2006)

for wireless networking (e.g., 5G). Visual monitoring may be carried out through drone technologies, increasing overall safety and integrity by more observation, more regular checks, more details, and fewer access to staff. (Brechan et. al. 2018b). Both API RP 90 (2006) and ISO 16,530-1 (2017) delineate the operation limits of an annulus as depicted in Fig. 10.

Wellhead and tree maintenance Servicing and maintenance programs of wellhead and X-tree are tools to verify the functionality of these components.

Similar structure was defined by (Andersen 2006) for WIM program. Figure 11 depicts interconnected elements of good WIMS.

Gulf of Suez Petroleum Company (GUPCO) rolled out first version of WI policy in (2010) to define accountabilities and responsibilities across the major elements of operating and intervention procedures, tubing/casing annulus, X-tree, and SSSV integrities.

Sparke et al. (2011) identified the main backbones of WIM to be seven pillars;

- Dedicated personnel and teams.

- Policies and procedures of the corporate.

- Well design and operating envelope for all wells.

- Inspection and verification holistic system.

- Failure management and analysis.
- System of data management and reporting process.

- Auditing.

The five essential components in the management system that had been listed by Sparke et al. (2011) are well construction envelope, well failure matrix, wells register, allowable leakage criteria, and WI software. Table 2 shows brief description of these components.

Gouda and Aslam (2018) specified three main phases that constitute WIMS. The first phase is assessment where we have effective hazard identification, safety critical element definition, performance standards development, verification process establishment. The second phase is intervening where we apply documentation, monitoring, tacking, and auditing. The third phase includes closing gaps and sustaining programs. In conclusion, WIMS is essentially designed to create a structure for handling significant hazards and incidents over the well life cycle.

To maintain WI at all times, all wells should be tracked and any well doesn't meet integrity standards shall be secured or closed-in, unless a risk-assessed deviation or dispensation is allowed (Wakama et al. 2004). A corporate focus is needed to ensure that all well stock achieves the minimum level of integrity standards as a way to manage the WI problem. This can eventually be built into WIM system that is vital element for the corporate to protect personnel and the environment.

Simply, the WIM System is a set of crisscrossing systems, standards, policies, reports, and performance monitoring platform to handle WI issues. To some degree, the performance of the program implementation would depend on the coordination between the inter-related parts. To avoid potential risks and production interrupts in the field, every well requires maintenance throughout its designed life time. If a well is not integral, it can represent a significant threat to the people, environment, and assets. Therefore, structural WI control in the upstream petroleum industry is receiving as much attention as reservoir or production management (Daghmouni et al. 2010).

Almukhaitah and Haldar (2013) addressed that the primary goals of E\&P business are to maximize the service life of wells and minimize the potential danger of sudden release of hydrocarbons throughout the well lifespan. Maintaining WI has therefore become as critical as
Table 2 Essential components in the management system (Sparke et al. 2011)

\begin{tabular}{ll}
\hline Component & Definition \\
\hline Well Construction Envelope & to determine operating limits \\
Well Failure Matrix & to identify failure conditions and dispensation cases \\
Wells Register & to have unified data base of all well stock in the corporate \\
Allowable Leakage Criteria & adopting worldwide standards \\
Well Integrity Software & to be user friendly and easily accessible \\
\hline
\end{tabular}


developing reservoirs without risking people lives, causing environmental pollution, or damaging company assets.

Having an intensive WIMS is important for ensuring continuous production stability, profitable operational activities, and a zero-leak target. Technological advances, combined with experience-based skills and lessons learnt from the past, should play a progressively significant part in solving the WI issues that arise in the coming years (Smith et al. 2015).

\section{Well integrity maturity}

It is very critical to involve WI in all phases of well life cycle (Ceray et al. 2014). This helps to alleviate most of possible malfunctioning scenarios of well components during well lifespan. The authors introduced the principle of maturity model (Fig. 12) and found that if there is no effective system of WIM in the field, the problems of integrity will be tackled

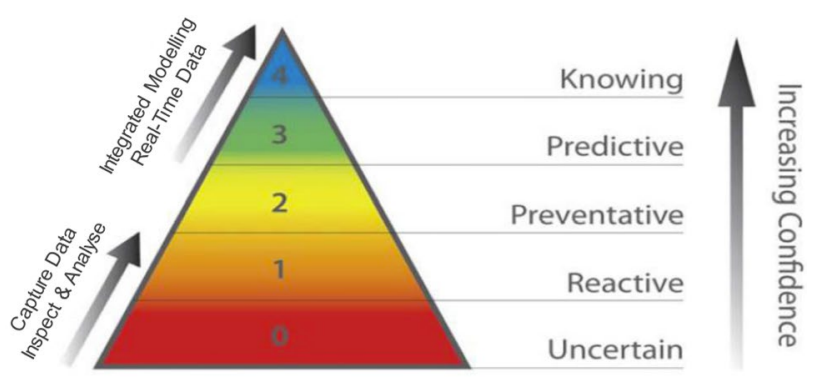

Fig. 12 Well integrity maturity model (Ceray et al. 2014) as a reactive approach. This necessitates the involvement of a robust system to ensure the WI is sustained all the time.

There are three essential elements in a maturity model. The first is a maturity level classification and identification. The second element is an evaluation method that can be employed to determine the maturity level of the organization and derive key maturity performance indicator. The third element is a framework intended to better organize the company's activities to make significant performance changes.

As maturity level of WI increases, this will help to have different benefits, such as operate the field at lower risk, extensive review of integrity conditions, minimize production deferral due to shut-in wells for integrity problems, detection of WI issues in timely manner, and better management of budgetary aspects and maintenance forward plan. Conceptually, maturity models reflect the advancement in the level of maturity of an enterprise in relation to a particular field of business. The poorer the degree of maturity, the stronger the intensity and severity of integrity issues. The fashion in which companies maintain their WI shows their status on their route of WI. Figure 13 shows the five levels of maturity.

In most occasions, companies at "level 0" apply the minimum legal requirements and perform routine testing of the relevant safety critical components. Then, at "level 1", operator begins data gathering and building knowledge of their wells to create corrective maintenance system. At "level 2," the operators set prescheduled system for preventative maintenance giving more attention to safety critical components. An operator managing its wells at a maturity

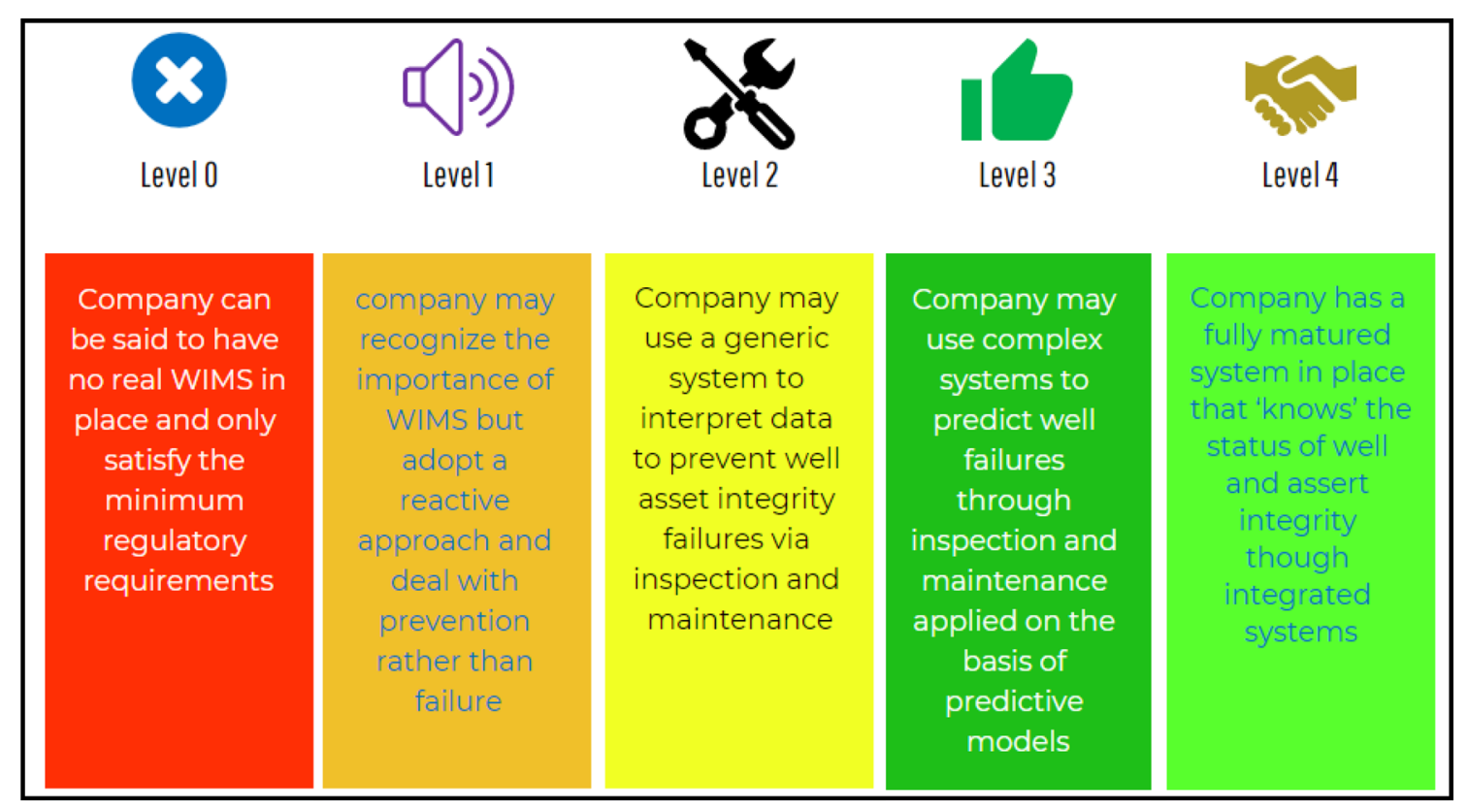

Fig. 13 Levels of WIMS maturity (Yakoot et al. 2020) 
"level 2" will typically collect data using spreadsheets or in-house data collection systems that allow basic analysis. The collection, storage, and use of data, even in its simplest form, are an important step along an operator's WI journey. Furthermore, a "level 3" WIMS enables long-term maintenance scheduling. Finally, "Level 4" can be anticipated to be more comprehensive, incorporated with a much wider asset portfolio and completely integrated with all pertinent corporate systems. Ceray et al. (2014) listed the transformation elements as;

- Application of WIM in all phases of well life time.

- Verifying all containment barriers at all times.

- Establishing strong database system.

- Creating proper key performance indicator (KPI) system.

- Integrating WIM system with corporate asset management system.

- Willingness to tackle all WI issues in a timely fashion.

Figure 14 shows, arbitrarily, time line for main common transformative elements to convert WI system from firefighting to strategic WIMS.

Similarly, Kumar et al. (2014) manifested the Paradigm Shift from reactive to predictive approaches because of its benefits compared to the drawbacks of reactive approach (Table 3).

The maturity pyramid (Fig. 15) shows that the importance of the data increases when it can be measured and used to optimize and accurately predict the future (Corneliussen 2017). Smith et al. (2016) established WIM pyramid equivalent to Data Information Knowledge Wisdom (DIKW) information science pyramid (Fig. 16). The authors indicated how data can be renovated into actions that maintain business objectives, including production.
Table 3 Drawbacks of the reactive approach versus the benefits of the predictive approach (Kumar et al. 2014)

Drawbacks of the reactive approach

It is usually after the event

Problem-solving strategies are very expensive because most approaches require a rig

If the situation is severe, there could well be control situation

It may contribute to a loss of assets

Benefits of the predictive approach

It offers a greater estimation of the safety status of the well in terms of integrity

The problems can be predicted

The remedies to the problems found are less expensive and simple to fix

Well control concerns are eliminated

It allows analyzing the source of the problem and its prevention

\section{Well barrier diagram}

The cornerstone idea of WI is the barrier concept (Bilogan et al. 2019). A robust WI system should have the proper safety barriers in place; acknowledged, tested, validated, and monitored. It should also have adequate contingencies in the event of the failure of these primary barriers (Santos 2014). O\&G wells are simply conduit of hydrocarbons from reservoir to the surface but in controlled manner. To control hydrocarbon flow from the well into the surface, at least two independent and tested barriers should be available. This is called two-barrier philosophy in WI (Chishti et al. 2015). The authors classified the two available barriers as primary envelope which acts first against any unintended hydrocarbon release and then comes the turn of secondary barrier if there is any failure in the primary barrier. Well barrier envelope is illustrated in Fig. 17.

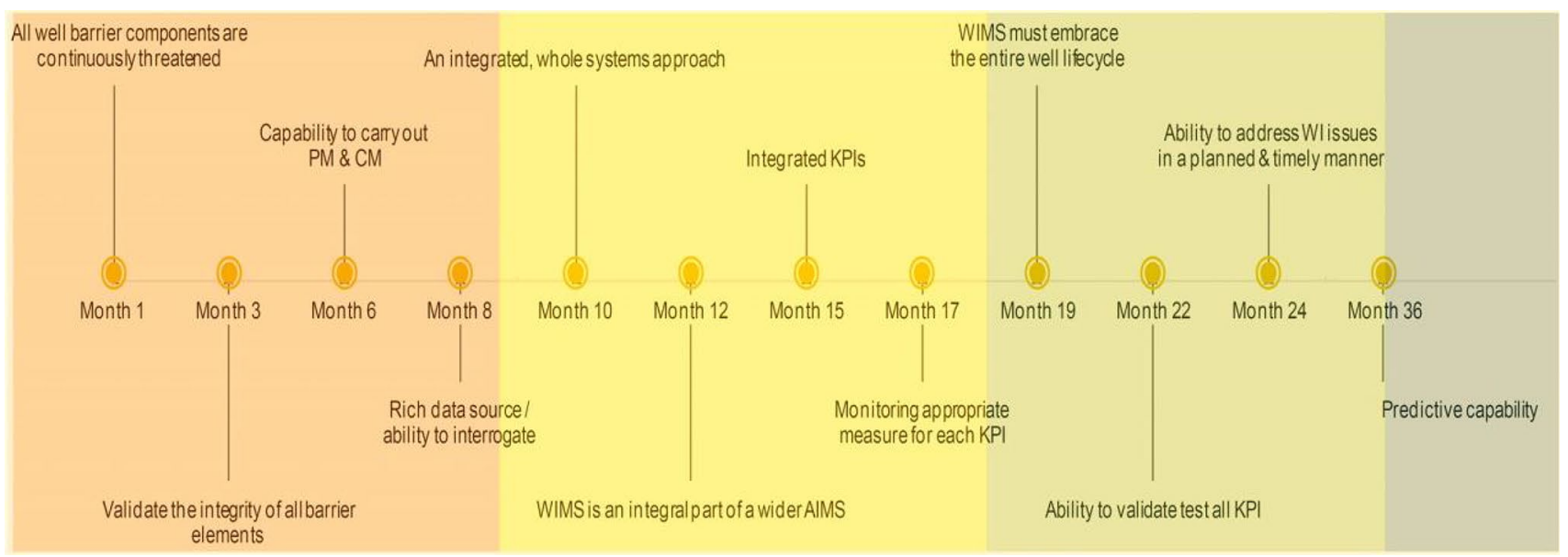

Fig. 14 Transformative elements of WIMS (Ceray et al. 2014) 


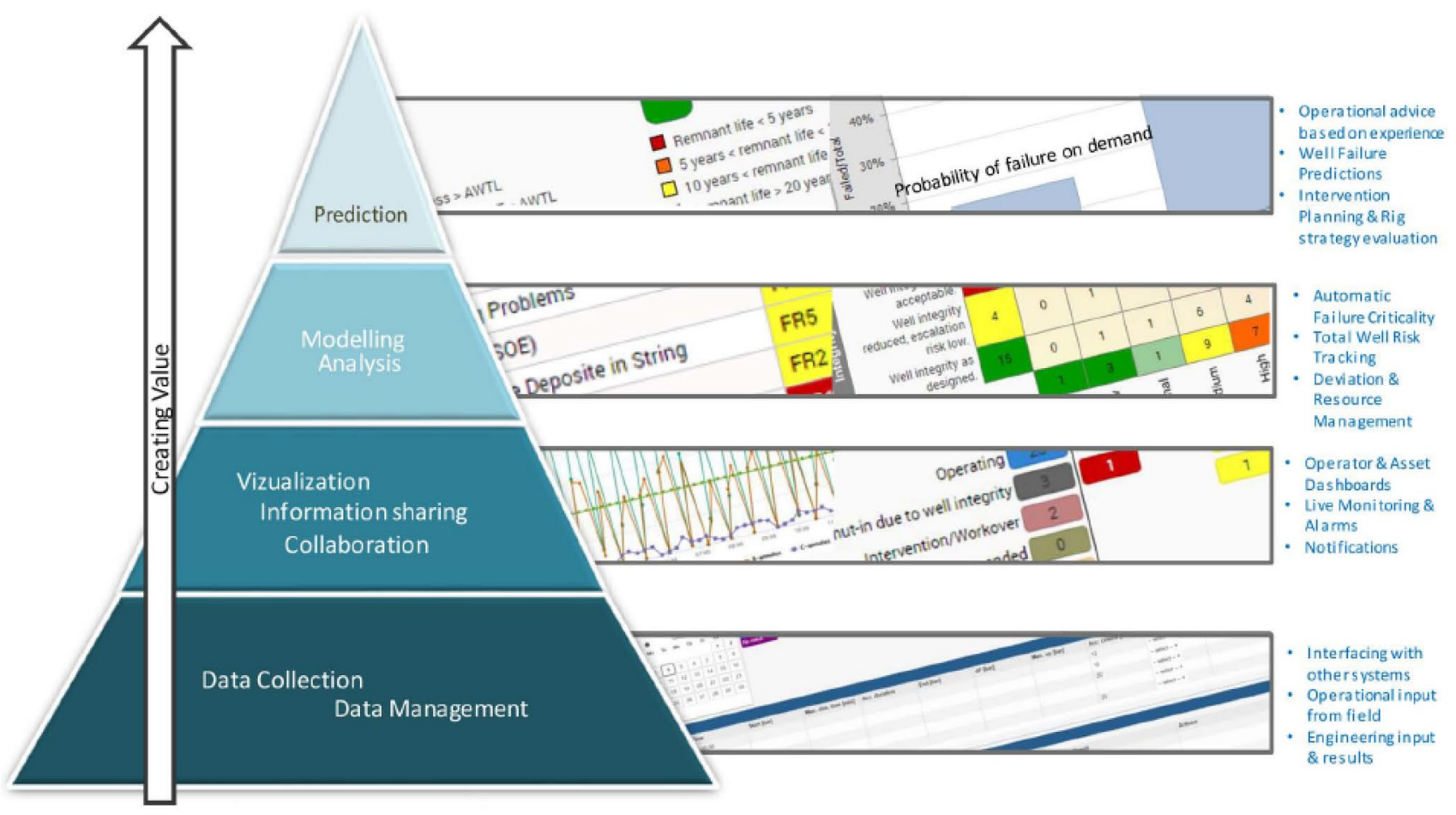

Fig. 15 Maturity pyramid (Corneliussen 2017)

\section{DIKW Pyramid}

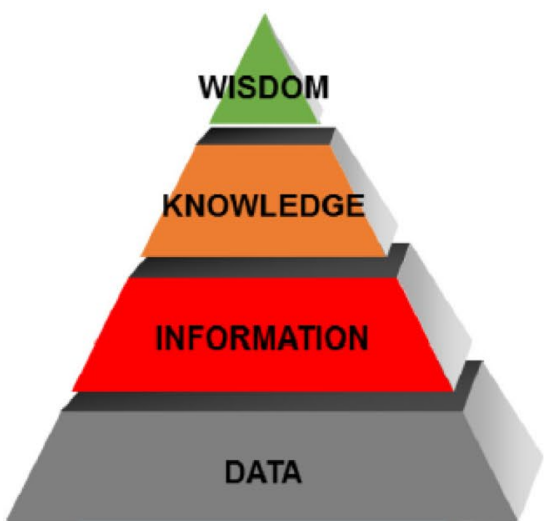

\section{WIM Pyramid}

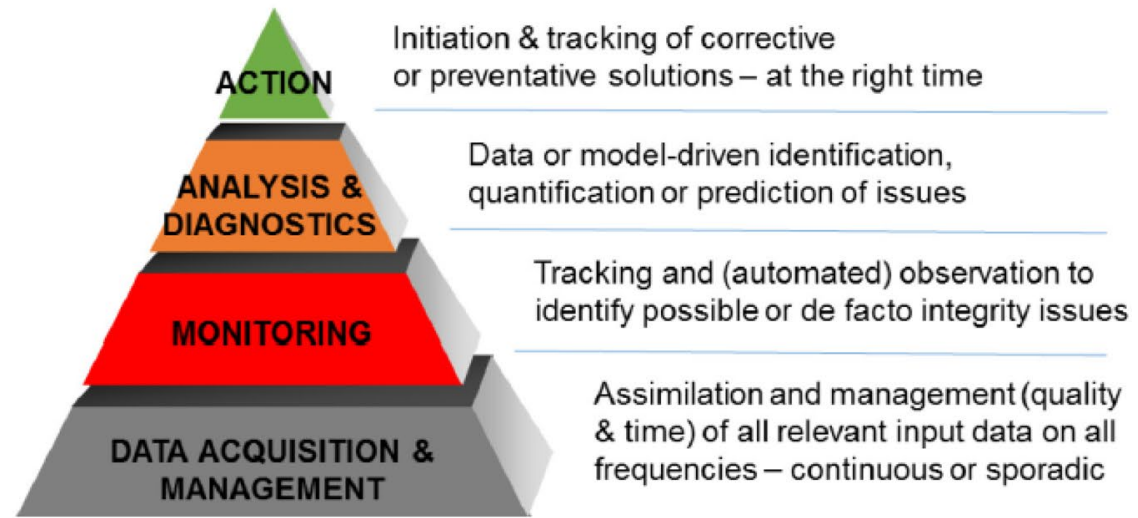

Fig. 16 WIM data pyramid (Smith et al. 2016)

Andersen (2006) found that the references for barrier criteria are the industry standards (e.g., ISO, API, and NORSOK), the company procedures, the guidelines, and the experience from operations. Some of the common WI problems where breach and failure of envelops occur are (Calosa et al. 2010; Bybee 2011):

- stresses acting at wellheads, which are not secured,

- leaking valves at wellheads and X-trees,

- corrosion of well components downhole and surface,
- failure of cement bonding between casing and formation, and

- casing failures such as elongation, drop due to top soil compaction, reservoir subsidence, etc.

WI is a lifelong process and does not end at completing and delivering wells as per expectations. Most of the initiative is to preserve wells inside their operational envelopes during their lifespan and to cope with any problem in a controllable manner. Getting the appropriate barrier in place is essential for any rising problem not to intensify, 
Fig. 17 Primary and secondary barrier envelopes (Al-Ashhab et al. 2004)

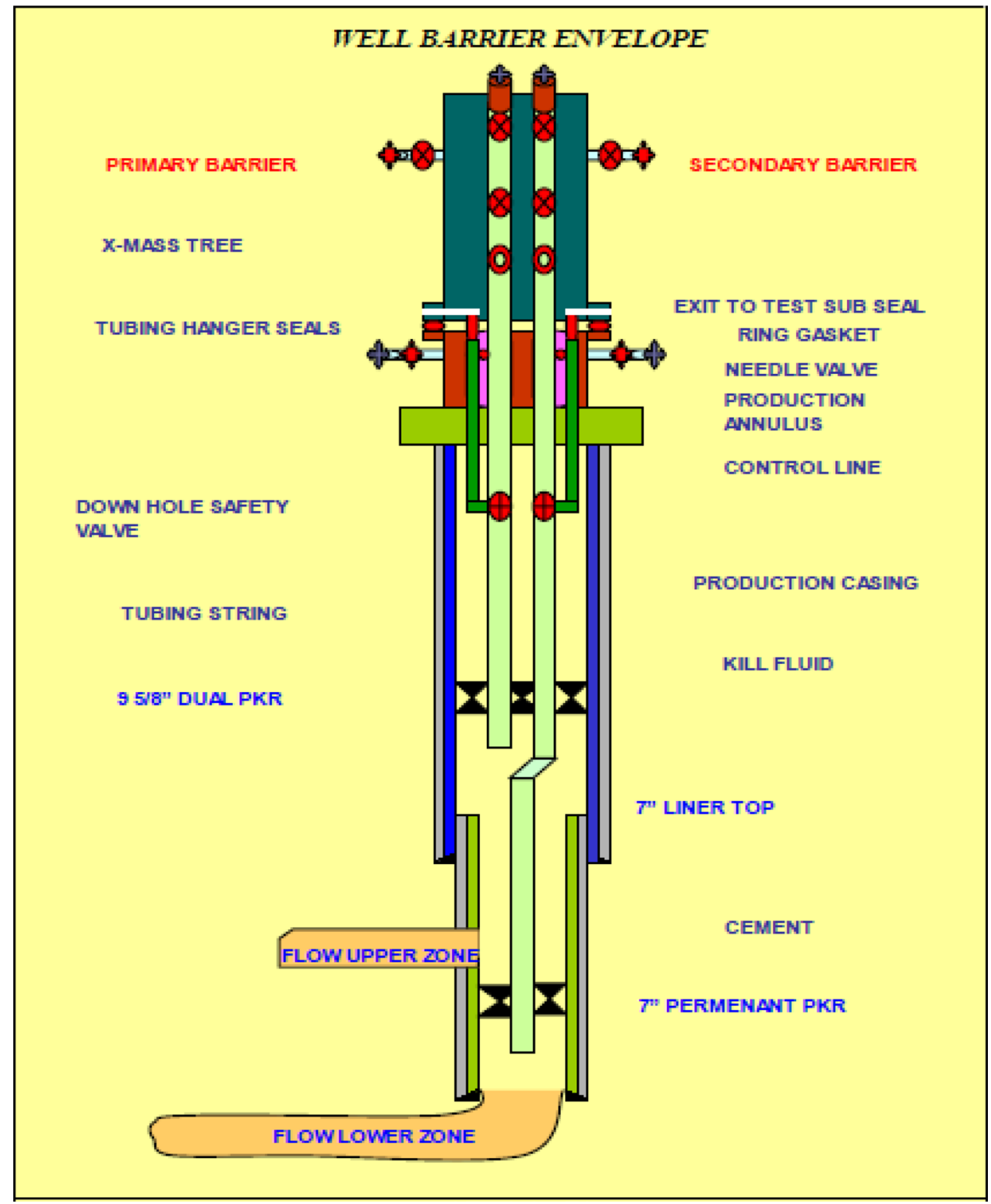

which enables sufficient time to react and resolve them. Keeping a comprehensive WI system to handle well-stock is one of the top priorities for the company assets (Kareem and Ali 2015). A matured WI system must resolve issues where a barrier envelope breach is identified and takes steps to maintain protection and at the same time leads to high efficiency and streamlined performance. Effective WI is about managing safety often against cost (Corneliussen 2017).

\section{Risk assessment}

A strong system of WI depends on techniques such as design basis, risk assessment (RA), change management, and action plans (Santos 2014). Risk management systems allow oil companies to assess the emerging problems and risks of drilling and exploration. It also enables to establish appropriate emergency plan and apply risk reduction mitigation (Tabibzadeh and Meshkati 2014). Risk assessment in WI problems enables to rank potential risks and provide source for risk mitigation and better resource allocation (Naiyan et al. 2018).

RA starts with a procedure for identifying the risk level of the individual wells and then goes on to evaluate the "impact to" and the total asset risk level (ISO 16,530-part 1 and 2). Generally, there are three types of RAs for WI operation; 1) qualitative RA, 2) quantitative RA, and 3) failure mode, effects and criticality analysis (FMECA). Failure mode is always a core part in risk analysis of any WI status. RA simply involves the investigation of different failure scenarios of single barrier element. This is done to identify probability of failure and consequences 
of this failure, which are both defining the risk. Dethlefs and Chastain (2012) argued that Qualitative assessment is very boring and tedious task. RA for each well-barrier failure scenario involves:

- Determining the likelihood and consequences of each of the scenarios being considered.

- Risk is computed for each scenario, which is the intersection between the likelihood and consequence.

- Each scenario is evaluated thoroughly before moving on to the next scenario. The process is repeated until all scenarios are evaluated.

- This will be repeated for each well or group of wells in the stock to be evaluated.

Smith et al. (2016) related the advantages of holistic risk control through holistic WIMS, with costs and production, and concluded strong interrelation between all of them because any improvement in one would have an effect on the other. The principal element in which holistic WIMS improves production is by risk identification and active avoidance of WI problems. Every well that is left in service instead of being shut-in for WI problems can have a huge effect on field performance. Generally, any WI problem would have a larger or smaller effect on production, either by forcing the well to be shut down or by in any manner disrupting production.

WIM begins at the well-design level and extends across the well life cycle. RA is growing complex and challenging as well as becoming older. Investment in gathering reliable data remains the secret to risk reduction and greater forecasting of future failures. Traditional techniques to WIMS are primarily used to diagnose failure. Now, there is a conceptual change, due to the innovative technologies at our hands, to take a predictive approach to predicting an issue before it occurs (Kumar et al. 2014). Performing RA is one of the routine activities in
WIMS that should be handled by software (Brechan et. al. 2018a). There is continuous emphasis on RA, as it always constitutes strategic element in WI value chain. Fjågesund (2018) perfectly indicated this value as shown in Fig. 18. Some important approaches for risk assessment are summarized in Table 4.

\section{Analytics principles in well integrity management}

It is very important to have all of the well parameters be constantly tracked, registered, documented and evaluated to ensure that well quality is preserved and that any variances be automatically noticed and handled (Chitale et al. 2010). El-Sayed et al. (2012) reviewed the literature and found that there is shortage in literature about different phases of applied management systems to control WI of certain field. The literature lacks perceptions about measuring the quality of WI system performance. Measuring level of system quality defines critical points for further development. El-Sayed et al. (2012) perused this point and developed new quality index as a key performance indicator (KPI) to suit the core businesses in their company. The quality index was established as hierarchal levels to allow different steps of focus on the operational activities. The key elements selected for quality index that are capable of achieving the company's quality objectives by continuous improvement. This is explained in Figs. 19 and 20 that show the selected core business areas to measure improvement in quality performance and different levels of quality Index and weight of elements in each level, respectively.

Anders et al. (2015) used analytics principles to handle the integrity of a large stock of wells. A variety of well performance information is collected, including wellhead and annulus pressures, production rates, wellhead and X-tree valve tests, and inspections of surface facilities. Critical parameters were defined for the wells such as limit of annulus pressures, anomalies, mandatory tests, preventative

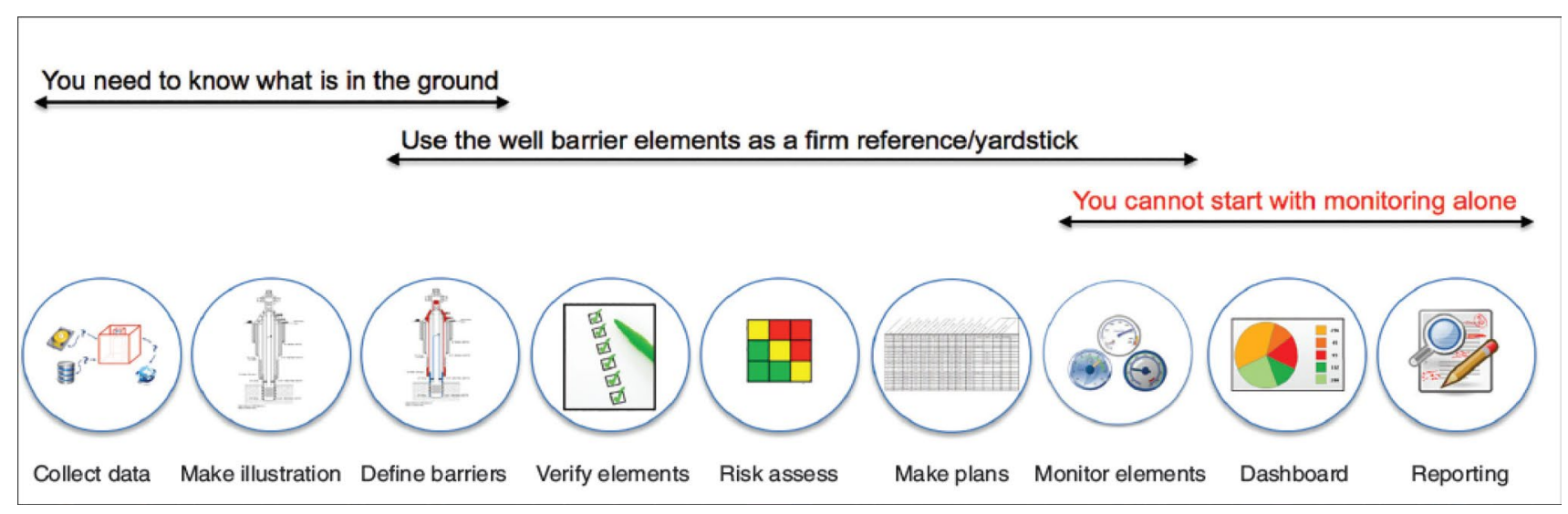

Fig. 18 How to build robust well integrity value chain (Fjågesund 2018) 
Table 4 Review of risk assessment approaches

\begin{tabular}{|c|c|}
\hline Publication & Innovation \\
\hline Kandil (2001) & $\begin{array}{l}\text { Used hazards and operability study (HAZOP), hazards identification (HAZID), and environment impact assess- } \\
\text { ment (EIA) methods to establish risk assessment program for managing pipeline failures in gas-lift operated } \\
\text { field in Gulf of Suze (GOS) }\end{array}$ \\
\hline Dethlefs and Chastain (2012) & $\begin{array}{l}\text { Linked between the well integrity definition and necessity to have deep analysis and comprehension of associated } \\
\text { risks, whenever event of undesired flow occurs }\end{array}$ \\
\hline Loizzo et al. (2015) & $\begin{array}{l}\text { Studied aquifer pollution-in Paris basin fields-due to injector corrosion and by using evidence-based risk- } \\
\text { assessment approach, they were able to identify the risk of high leakage and which wells require prompt action } \\
\text { to reduce level of risk }\end{array}$ \\
\hline Ajimoko (2016) & $\begin{array}{l}\text { Defined quantitative RA methodology as a predictive analysis approach that can be used to determine WI risks } \\
\text { when evaluating all consequences and likelihood }\end{array}$ \\
\hline Mundie and Wilson (2016) & $\begin{array}{l}\text { Developed a new approach that has been leveraged to deliver operative communication in the risk-ranking pro- } \\
\text { cess and helps to quantify the risk from wells }\end{array}$ \\
\hline Abimbola et al. (2016) & $\begin{array}{l}\text { Adapted bowtie model and Bayesian network to identify potential failure scenarios during operations of casing } \\
\text { and cementing }\end{array}$ \\
\hline Smith et al. (2016) & $\begin{array}{l}\text { Related the advantages of holistic risk control through holistic WIMS, with costs and production, and concluded } \\
\text { strong interrelation between all of them }\end{array}$ \\
\hline Naiyan et al. (2018) & $\begin{array}{l}\text { Presented novel risk-assessment model for well integrity by identifying the risk associated with barrier failure, } \\
\text { investigating risk factor in production phase, and establishing risk matrix based on analytical methods }\end{array}$ \\
\hline Gouda and Aslam (2018) & $\begin{array}{l}\text { Performed risk assessment to help identifying any related weaknesses in the well that may cause intolerable risk } \\
\text { and recommend potential solutions and/or corrective actions }\end{array}$ \\
\hline Zhao et al. (2019) & $\begin{array}{l}\text { Innovated a model to assess the well integrity failure of underground gas storage using hierarchical Bayes analy- } \\
\text { sis }\end{array}$ \\
\hline Abreu et al. (2019) & $\begin{array}{l}\text { Proposed an adapted preliminary risk analysis approach related to well integrity. The proposed approach assumes } \\
\text { the risky events as combinations of well barrier failures and/or incidents that involve them }\end{array}$ \\
\hline Adeyinka et al. (2020) & $\begin{array}{l}\text { Applied a Swiss-cheese model to analyze safety devices related to well integrity. Risk factor was assigned for } \\
\text { each device indicating its relative importance and then used to create a risk-index for easier comparison and } \\
\text { prioritization of well interventions required }\end{array}$ \\
\hline
\end{tabular}

maintenance, and frequency of tests. For a large well stock, assessing risks of all failure scenarios and categorizing overall well risk is tedious task. Application of analytical principles helped the authors to deploy all the available information to control WI.

Zahacy and Demirdal (2019) described WIM in a systematic way to mitigate all the potential risks, as a major challenge, especially in brown offshore fields. One of the dominant reasons for that challenge is the bad conditions of assets and facilities, where the surface and subsurface safety critical elements, including casing strings, cement sheaths, wellhead valves and X-tree components, and in some wells packers and tubing strings leading to failure and damage of surface and subsurface well barrier elements. Such assessments are generally highly subjective, and depend on the experience of the team members.

\section{Applications of well integrity management}

Spowage et al. (2018) depicted that the overall effect of integrity management has created a great deal of benefit in terms of minimizing downtime, enhancing well-control and safety factors, and eliminating unplanned maintenance operations. In fact, impairment of WI will contribute to significant incidents with severe threats to individuals, equipment, and the environment. Non-integral wells are widespread in brown fields, which are becoming a challenge in restoring integrity and functionality, particularly for those aged wells. Active WI assurance has resulted in a significant range of benefits relevant to well reliability, better operability, cost reductions and a sustainable annual production target. Daghmouni et al. (2010) structured diagram to show the road map of WIMS application (Fig. 21).

Owning unified WI standard makes all of the business units align with each other. This ensures that a common set of guidelines is extended on all assets in respect to the same integrity requirements set at the managerial level. In other words, each well is managed in the same way to ensure efficient management. Ultimately, the company has the potential to analyze processes through business units, evaluate compliance problems effectively, and concentrate better on intervention strategies across the most sensitive fields (Gell et al. 2015).

Priwanza et al. (2017) developed a WIM tool that acts as a follow-up tool and unified database for concerned teams within the organization. The tool depends on two main components to be assessed to identify integrity status of any well, starting with two barrier envelopes (primary and secondary), and annulus management. 
Fig. 19 Nine core business areas were selected to measure improvement in quality performance, where the corporate objectives can be assured (ElSayed et al. 2012)
Fig. 20 Different levels of quality Index and weight of elements in each level (El-Sayed et al. 2012)
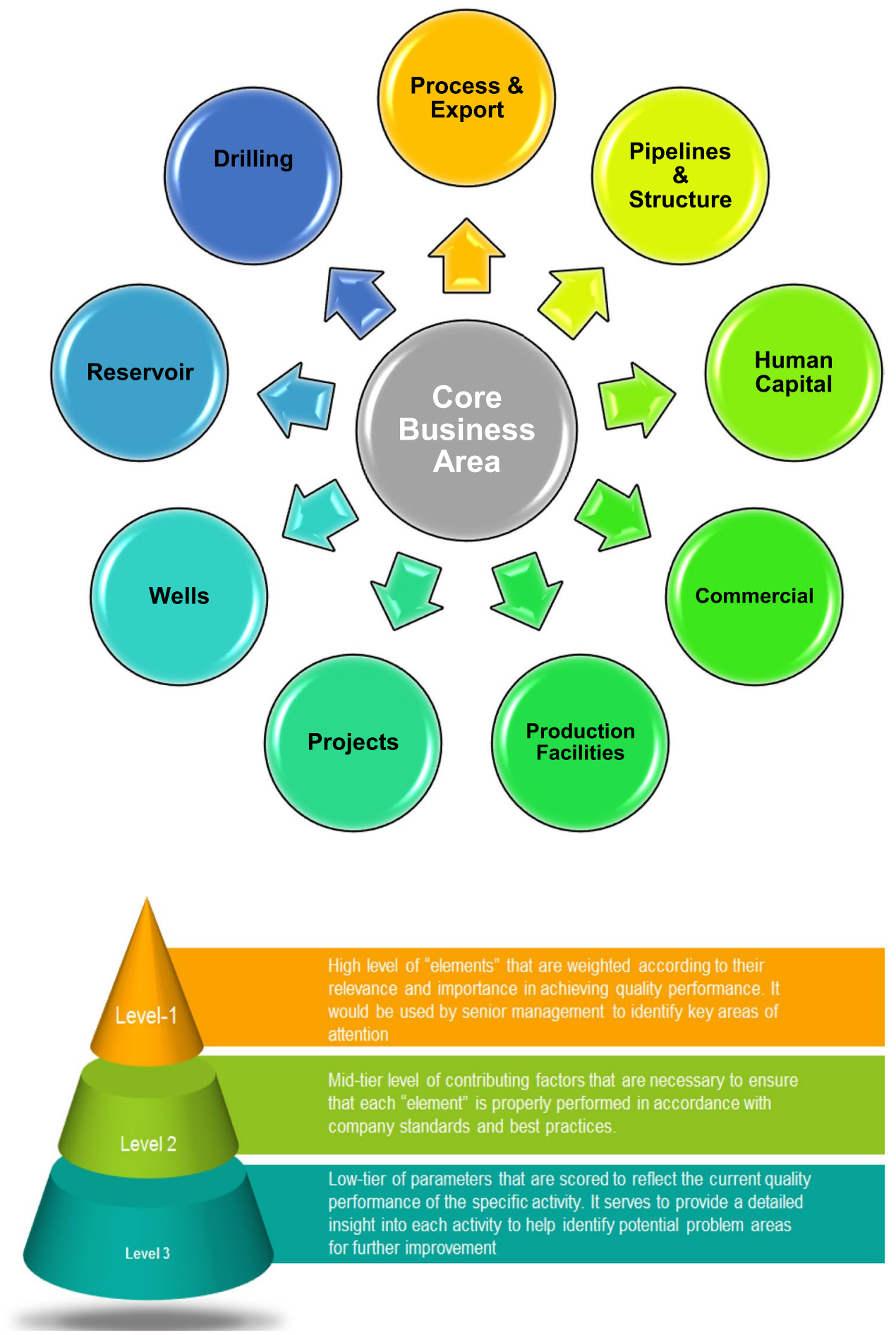

\section{Summary and conclusions}

This article unprecedentedly summarizes the experience and improvements in the application of WIMS and its essential principles. The evolution of WI and structure of WI program is overviewed. Moreover, it comprehensively discusses the application of WIMS and their level of maturity. Various approaches of RA have been covered as well as analytics principles in well integrity management. On the other side, multiple aspects of WI discipline have been reviewed and explored which didn't allow for profound scrutiny of each sub-discipline independently. Further studies with more individual focus on RA techniques, application of data analytics in WIMS, and system maturity are therefore suggested (for more in-depth and detailed understanding of WIMS 


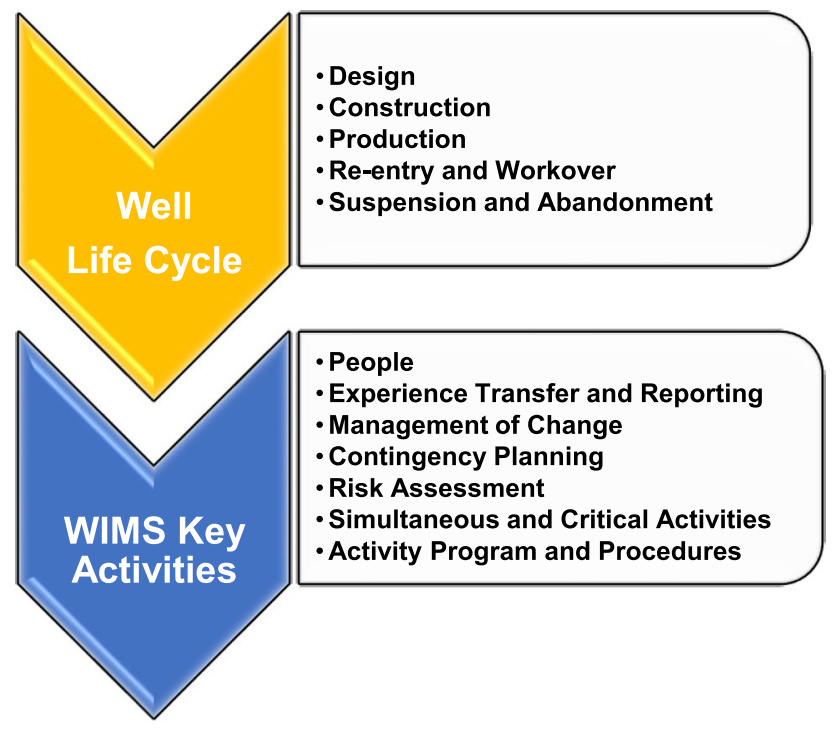

Fig. 21 Road map for WIMS application (Daghmouni et al. 2010)

maturity and benchmarking; the reader is referred to Yakoot et al. 2020). Based on this review, the following conclusions can be drawn:

1. Although attentions to WI discipline were started after Macondo disaster, it was few years ago that real progress was made in this area. WIMS was established in many O\&G companies all over the world, especially after 2010. However, level of system maturity differs from organization to another.

2. Well integrity data management is a standalone system incorporated inside WIMS, and has its own coherent level of maturity. Not all companies achieved remarkable progress in data maturity. This is mainly because O\&G business adopted artificial intelligence and internet of things later than other industries.

3. Applying WIMS can protect people lives, environment, and assets. It can also help operate wells safely, guarantee company from any possible moratorium, keep good society and public image of the company, and identify and locate new oil gains and/or restoration possibilities.

4. It was proved that competent staff in operations, well servicing, and production serve a significant role in management of WI. Relocating the well integrity staff nearby to field activities keeps vigilance and offers a process for identifying potential problems.

5. There is an abundance of WIM approaches that can be found in the literature. However, the developed approaches are mostly limited to a certain field (or group of fields) for which it is developed. Consequently, they lack the universality that is pursued after in the industry.
6. The literature is short of adopting artificial intelligence and machine learning to predict and analyze WI status of oil/gas producers. Prior studies have noted the importance of Machine learning as a very powerful instrument; however, very little was found in the literature on the subject of WIM and risk ranking wells in terms of barrier envelopes.

WIM is indispensable system that must be applied and matured for well lifecycle. Risk assessment of WI status enables classifying probable risks and considered source for risk alleviation and better resource provision.

\section{Recommendations}

Many studies have covered almost all of the main elements of the WIMS in well life cycle; however, the draw conclusions provide the following important implications and insights for future research:

1. Innovating a model that provides WI status and risk classification with minimum possible error compared to the true values. At the same time, the created model should be simple with lower uncertainty in the employed parameters compared to the team-analyzed values.

2. Developing a smart tool for tracking high-risk wells in particular, which offers a safer way of managing production hazards and prioritizing well services/management approaches. This can help enhancing organizational efficiency and minimizing downtime.

3. Evolving effective failure warnings that have a clear effect on WI. In addition, they empower fast and consistent proactive recognition of field problems affecting production.

4. Well integrity should be modernized and step-up from regular spreadsheets and non-user friendly and full-ofbug softwares to benefit from computational empowerment and self-educating machine to attain ultimate maturity in management and data maturity systems.

It is obvious that the WIMS and RA approaches require overlong extensive and comprehensive understanding and analysis. The most recent studies on the application of WIMS, during well life cycle, have been covered in this manuscript. This comprehensive review has highlighted different systems and approaches of WIM and risk assessment. Challenges and recommendations for future research are also discussed and thoroughly presented. However, this study has some limitations which should be noted for addressing in future studies. First, competency level of involved staff was overlooked in almost all reviewed WIMS in spite of their significant role. This put efficiency of WIMS, lacking 
essential controlling parameter, in big doubt. Second, we were unable to evaluate the efficiency of introduced WIMSs when being used in different fields with different operation conditions because data of wells' inventory in each system weren't available. This keeps level of system effectiveness as relative matter.

Acknowledgements The authors would like to express appreciation for the support of the Gulf of Suez Petroleum Company (GUPCO) and permission to publish this work. The authors would also like to acknowledge Prof. Ahmed A. Elgibaly who passed away on January 15, 2021. May Allah forgive his sins, have mercy on him, and admit him Jannatul Firdauss. The first author would like to extend his appreciation for the faculty members in the department of petroleum engineering, Suez University, Egypt, for their continuous encouragement and support.

Funding The author(s) received no specific funding for this work.

Open Access This article is licensed under a Creative Commons Attribution 4.0 International License, which permits use, sharing, adaptation, distribution and reproduction in any medium or format, as long as you give appropriate credit to the original author(s) and the source, provide a link to the Creative Commons licence, and indicate if changes were made. The images or other third party material in this article are included in the article's Creative Commons licence, unless indicated otherwise in a credit line to the material. If material is not included in the article's Creative Commons licence and your intended use is not permitted by statutory regulation or exceeds the permitted use, you will need to obtain permission directly from the copyright holder. To view a copy of this licence, visit http://creativecommons.org/licenses/by/4.0/.

\section{References}

Abimbola M, Khan F, Khakzad N (2016) Risk-based safety analysis of well integrity operations. Saf Sci 84:149-160. https://doi.org/ 10.1016/j.ssci.2015.12.009

Abreu DTM, Morais CHB, Santos JR et al (2019) Well integrity: preliminary risk analysis for different well life cycle phases. Presented at the ASME 2019 38th international conference on ocean, offshore and arctic engineering, Glasgow, Scotland, United Kingdom, 9-14 June. OMAE2019-96280. https://doi.org/10.1115/ OMAE2019-96280

Adeyinka A, Tsakporhore A, Arije O et al (2020) Rethinking well integrity for sustainability: adopting a risk based approach. Presented at the SPE Nigeria annual international conference and exhibition, Virtual, 11-13 August. SPE-203672-MS. https://doi. org/10.2118/203672-MS

Ahmed SF, Elkholy M, Warnken D et al (2007) Design and early implementation of a well integrity management system in an offshore brownfield operation. Presented at the international petroleum technology conference, Dubai, UAE, 4-6 December. IPTC11678-MS. https://doi.org/10.2523/IPTC-11678-MS

Ajimoko OOT (2016) Quantitative risk analysis of well integrity issues in deepwater well intervention. Presented at the offshore technology conference Asia, Kuala Lumpur, Malaysia, 22-25 March. OTC-26830-MS. https://doi.org/10.4043/26830-MS

Al Khamis MN, Al Khalewi FT, Al Hanabi M et al (2014) A comprehensive approach of well integrity surveillance. Presented at the international petroleum technology conference, Doha, Qatar, 19-22 January. IPTC-17465-MS. https://doi.org/10.2523/ IPTC-17465-MS
Al Muailu HA, Al Syed S, Al Omairen K et al (2013) Systematic approach to integrate a comprehensive surface and subsurface well integrity management system. Presented at the SPE Middle East oil and gas show and conference, Manama, Bahrain, 10-13 March. SPE-164425-MS. https://doi.org/10.2118/164425-MS

Al-Ashhab J, Afzal M, Emenike CO (2004) Well Integrity Management System (WIMS). Presented at the Abu Dhabi international conference and exhibition, Abu Dhabi, UAE, 10-13 October. SPE-88696-MS. https://doi.org/10.2118/88696-MS

Almukhaitah AA, Haldar S (2013) Effective well integrity management in a mature sour oil field. Presented at the international petroleum technology conference, Beijing, China, 26-28 March. IPTC16767-MS. https://doi.org/10.2523/IPTC-16767-MS

Anders J, Disbrow J, Dube A et al (2015) Analytics applied to well integrity. Presented at the SPE digital energy conference and exhibition, The Woodlands, Texas, USA, 3-5 March. SPE173434-MS. https://doi.org/10.2118/173434-MS

Anders JL, Rossberg RS, Dube AT et al (2008) Well integrity operations at Prudhoe Bay, Alaska. SPE Prod Oper 23(2):280-286. SPE-102524-PA. https://doi.org/10.2118/102524-PA

Andersen G (2006) Management: well-integrity management and profitability. J Pet Technol 58(7):40-42. SPE-0706-0040-JPT. https:// doi.org/10.2118/0706-0040-JPT

API RP 90 (2006) Annular casing pressure management for offshore wells, first edition. API, Washington, DC

Benjamin A, Cosmas N (2018) Integrated approach to well integrity data quality management initiative in Shell Nigeria. Presented at the SPE Nigeria annual international conference and exhibition, Lagos, Nigeria, 6-8 August. SPE-193456-MS. https://doi.org/10. 2118/193465-MS

Bilogan A, Elichev V, Binn-Tahir H et al (2019) A real-time well integrity monitoring workflow based on artificial intelligence and dynamic flow modeling. Presented at the BHR 19th international conference on multiphase production technology, Cannes, France, 5-7 June. BHR-2019-035. https://www.onepetro.org/conferencepaper/BHR-2019-035

Brechan B, Dale SI, Sangesland S (2018a) Well integrity risk assessment-software model for the future. Presented at the offshore technology conference Asia, Kuala Lumpur, Malaysia, 20-23 March. OTC-28481-MS. https://doi.org/10.4043/28481-MS

Brechan B, Sangesland S, Naaden C (2018b) Well integrity-next developments. Presented at the SPE/IADC Middle East drilling technology conference and exhibition, Abu Dhabi, UAE, 29-31 January. SPE-189403-MS. https://doi.org/10.2118/189403-MS

Brechan B, Sangesland S, Dale S (2019) Well integrity-managing the risk using accurate design factors. Presented at the SPE Norway one day seminar, Bergen, Norway, 14 May. SPE-195604-MS. https://doi.org/10.2118/195604-MS

Bybee K (2007) Well-integrity operations at Prudhoe Bay, Alaska. J Pet Technol 59(1):64-66. SPE-0107-0064-JPT. https://doi.org/10. 2118/0107-0064-JPT

Bybee K (2011) Well-integrity issues in Malacca Strait contract area. J Pet Technol 63(4):64-68. SPE-0411-0064-JPT. https://doi.org/ 10.2118/0411-0064-JPT

Calosa WJ, Sadarta B, Ronaldi R (2010) Well integrity issues in Malacca Strait contract area. Presented at the SPE oil and gas India conference and exhibition, Mumbai, India, 20-22 January. SPE-129083-MS. https://doi.org/10.2118/129083-MS

Ceray A, Borzel K, Spowage AC (2014) Well integrity-moving from firefighting to strategic planning. Presented at the SPE Asia Pacific Oil and Gas Conference and Exhibition, Adelaide, Australia, 14-16 October. SPE-171472-MS. https://doi.org/10.2118/ 171472-MS

Chishti K, El-Refai M, Nour El Din A et al (2015) Design and implementation of well integrity passport. Presented at the Abu Dhabi international petroleum exhibition and conference, Abu Dhabi,

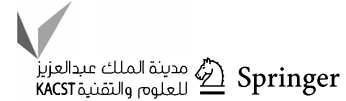


UAE, 9-12 November. SPE-177517-MS. https://doi.org/10.2118/ 177517-MS

Chitale AA, Blosser WR, Arias BJ (2010) Use of real-time data in well integrity management. Presented at the SPE intelligent energy conference and exhibition, Utrecht, Netherlands, 23-25 March. SPE-128688-MS. https://doi.org/10.2118/128688-MS

Corneliussen K (2017) Well integrity and reliability management in a life cycle perspective. Presented at the SPE Bergen one day seminar, Bergen, Norway, 5 April. SPE-185933-MS. https://doi. org/10.2118/185933-MS

Daghmouni H, El Manci M, Abdel Rady S A et al (2010) Well Integrity Management System (WIMS) development. Presented at the Abu Dhabi international petroleum exhibition and conference, Abu Dhabi, UAE, 1-4 November. SPE-137966-MS. https://doi. org/10.2118/137966-MS

D’Alesio P, Caramanico L (2015) Proactive well integrity management through the estimation of residual well life. Presented at the international petroleum technology conference, Doha, Qatar, 6-9 December. IPTC-18300-MS. https://doi.org/10.2523/ IPTC-18300-MS

Dethlefs J, Chastain B (2012) Assessing well-integrity risk: a qualitative model. SPE Drill Compl 27(2):294-302. SPE-142854-PA. https://doi.org/10.2118/142854-PA

Elrefai MA, Al Mutairi AM, Al Saadi M et al (2017) Inhouse design and implementation of well integrity database management system. Presented at the Abu Dhabi international petroleum exhibition and conference, Abu Dhabi, UAE, 13-16 November. SPE188726-MS. https://doi.org/10.2118/188726-MS

El-Sayed HS, Al-Marri F, Hussain A et al (2012) A novel approach to measuring the quality of well integrity performance in ADMAOPCO. Presented at the Abu Dhabi international petroleum conference and exhibition, Abu Dhabi, UAE, 11-14 November. SPE161160-MS. https://doi.org/10.2118/161160-MSs

Fjågesund T (2018) Robust well barrier and well integrity management. J Pet Technol 70(12):14-15. SPE-1218-0014-JPT. https://doi.org/ 10.2118/1218-0014-JPT

Gell C, Dawson M, Emslie M et al (2015) Well integrity management at premier oil and the benefits of implementing a well integrity data management system. Presented at the offshore technology conference, Houston, Texas, USA, 4-7 May. OTC-25950-MS. https://doi.org/10.4043/25950-MS

Gilbert R, Setiawan TB, Yaakub MY et al (2013) Bracing for rising challenges in well integrity management. Presented at the SPE Asia pacific oil and gas conference and exhibition, Jakarta, Indonesia, 22-24 October. SPE-165776-MS. https://doi.org/10.2118/ 165776-MS

Gouda MH, Aslam I (2018) Well integrity life cycle. Presented at the SPE international conference and exhibition on health, safety, security, environment, and social responsibility, Abu Dhabi, UAE, 16-18 April. SPE-190504-MS. https://doi.org/10.2118/ 190504-MS

Gulf of Suez Oil Company (GUPCO) (2010) Well integrity policy: version 1. Internal policy. Gulf of Suez Oil Company (GUPCO), Egypt

Hauge S, Okstad EH, Tinmannsvik RK et al (2013) Risk of major accidents: causal factors and improvement measures related to well control in the petroleum industry. Presented at the SPE Americas E\&P health, safety, security and environmental conference, Galveston, Texas, USA, 18-20 March. SPE-163775-MS. https://doi. org/10.2118/163775-MS

ISO 16530-1 (2017) Petroleum and natural gas industries —well integrity — part 1: life cycle governance, 1st edn. Geneva, Switzerland: International Organization for Standardization (ISO).

Kandil ME (2001) Efforts to persevere a risk assessment/integrity assurance for its aged hydrocarbon transfer pipelines. Presented at the SPE annual technical conference and exhibition, New Orleans,
Louisiana, USA, 30 September-3 October. SPE-71436-MS. https://doi.org/10.2118/71436-MS

Kareem H, Ali A (2015) Restoring and managing brownfield wells integrity to operate safely and reliably in south of Iraq. Presented at the Abu Dhabi international petroleum exhibition and conference, Abu Dhabi, UAE, 9-12 November. SPE-177885-MS. https://doi.org/10.2118/177885-MS

Kiran R, Teodoriu C, Dadmohammadi Y et al (2017) Identification and Evaluation of Well Integrity and Causes of Failure of Well Integrity Barriers (A review). J Nat Gas Sci Eng 45:511-526. https://doi.org/10.1016/j.jngse.2017.05.009

Kumar S, Al-Atwi MA, Al-Mulhim AK et al (2014) Inching toward complete well integrity management. Presented at the SPE international oilfield corrosion conference and exhibition, Aberdeen, Scotland, United Kingdom, 12-13 May. SPE-169607-MS. https:// doi.org/10.2118/169607-MS

Loizzo M, Bois A, Etcheverry P et al (2015) An evidence-based approach to well-integrity risk management. SPE Econ Mgmt 7(3):100-111. SPE-170867-PA.https://doi.org/10.2118/ 170867-PA

Ma L, Zhang K, Xie J et al (2020) Research progress and prospect of well integrity technology. J Power Energy Eng 8(7):45-54. https:// doi.org/10.4236/jpee.2020.87004

Miraglia S (2020) A data-driven probabilistic model for well integrity management: case study and model calibration for the Danish sector of North Sea. J Struct Integ Mainten 5(2):142-153. https://doi.org/10.1080/24705314.2020.1746013

Mundie G, Wilson S (2016) Data to language_-leveraging software to understanding and communicate well integrity risk throughout the organisation. Presented at the SPE intelligent energy international conference and exhibition, Aberdeen, Scotland, United Kingdom, 6-8 September. SPE-181054-MS. https://doi. org/10.2118/181054-MS

Naiyan Z, Zhi Z, Rui Z et al (2018) Comprehensive risk assessment of high sulfur-containing gas well. J Pet Sci Eng 170:888-897. https://doi.org/10.1016/j.petrol.2018.07.016

NORSOK D-010 (2013) Well integrity in drilling and well operations, 4th revision. Standards Norway (SN), Oslo, Norway

Priwanza H, Saputra R, Manalu D et al (2017) Development of well integrity management tool in Mahakam Block. Presented at the SPE/IATMI Asia Pacific oil \& gas conference and exhibition, Jakarta, Indonesia, 17-19 October. SPE-186281-MS. https:// doi.org/10.2118/186281-MS

Reichetseder P (2016) The Concept of Well Integrity in Gas Production Activities. Ecol Chem Eng S 23(2):205-213. https://doi. org/10.1515/eces-2016-0013

Samad SA, Tarmoom IO, Binthabet HA et al (2007) A comprehensive approach to well integrity management. Presented at the SPE Middle East oil and gas show and conference, Manama, Bahrain, 11-14 March. SPE-105319-MS. https://doi.org/10. 2118/105319-MS

Santos OLA (2014) Technology focus: well integrity. J Pet Technol 66(1). SPE-0114-0090-JPT. https://doi.org/10.2118/ 0114-0090-JPT

Smith CJB, Smith LM, Spowage AC (2016) The production benefits of effective well integrity management. Presented at the offshore technology conference Asia, Kuala Lumpur, Malaysia, 22-25 March. OTC-26698-MS. https://doi.org/10.4043/26698-MS

Smith L, Milanovic D, Smith C et al (2015) Keeping pace with changing well integrity management demands. Presented at the international petroleum technology conference, Doha, Qatar, 6-9 December. IPTC-18520-MS. https://doi.org/10.2523/ IPTC-18520-MS

Sparke SJ, Conway R, Copping S (2011) The seven pillars of well integrity management: the design and implementation of a well integrity management system. Presented at the SPE/ICoTA coiled 
tubing \& well intervention conference and exhibition, The Woodlands, Texas, USA, 5-6 April. SPE-142449-MS. https://doi.org/ 10.2118/142449-MS

Spowage AC, Copping S, Lunt G et al (2018) Management of well integrity across divested upstream assets. Presented at the offshore technology conference Asia, Kuala Lumpur, Malaysia, 20-23 March. OTC-28280-MS. https://doi.org/10.4043/28280-MS

Tabibzadeh M, Meshkati N (2014) Learning from the BP deepwater horizon accident: risk analysis of human and organizational factors in negative pressure test. Environ Syst Decis 34:194-207. https://doi.org/10.1007/s10669-014-9497-2

Wakama M, Eta E, Adeniyi A (2004) Well integrity management in Shell Nigeria. Presented at the Nigeria annual international conference and exhibition, Abuja, Nigeria, 2-4 August. SPE88934-MS. https://doi.org/10.2118/88934-MS

Yakoot MS, Elgibaly AA, Ragab AM S. et al (2020) A comprehensive review and analysis of maturity model for well integrity in
Brownfield. Presented at the IADC drilling middle East 2020 conference \& exhibition (Virtual), 14-15 December. https://www. iadc.org/wp-content/uploads/2020/12/ME20-Mostafa-Yakoot.pdf

Zahacy TA, Demirdal B (2019) Risk-ranking approach for thermal well integrity using readily available application, well and operational parameters. Presented at the SPE annual technical conference and exhibition, Calgary, Alberta, Canada, 30 September-2 October. SPE-196081-MS. https://doi.org/10.2118/196081-MS

Zhao L, Yan Y, Wang P et al (2019) A risk analysis model for underground gas storage well integrity failure. J Loss Prev Process Ind 62:103951. https://doi.org/10.1016/j.jlp.2019.103951

Publisher's Note Springer Nature remains neutral with regard to jurisdictional claims in published maps and institutional affiliations. 